\title{
Modelling of CFRP-Strengthened RC Shear Walls with a Focus on End-Anchor Effects
}

by

\author{
Said Ali Said \\ A thesis submitted to \\ The Faculty of Graduate and Postdoctoral Affairs \\ In partial fulfillment of the requirements for the degree of
}

\section{Master of Applied Science}

Ottawa-Carleton Institute for Civil and Environmental Engineering

Department of Civil and Environmental Engineering

Carleton University

Ottawa, Ontario

January, 2021

(C) 2021, Said Ali Said 
The undersigned hereby recommends to the

Faculty of Graduate and Postdoctoral Affairs

acceptance of the thesis

\title{
Modelling of CFRP-Strengthened RC Shear Walls with a Focus on End- Anchor Effects
}

\author{
submitted by Said Ali Said
}

in partial fulfillment of the requirements for the degree of

Master of Applied Science

Dr. David Lau, Thesis Supervisor

Dr. Vahid Sadeghian, Thesis Co-supervisor

Dr. George Hadjisophocleous, Department Chair

Ottawa-Carleton Institute for Civil and Environmental Engineering

Department of Civil and Environmental Engineering

Carleton University

January, 2021 


\section{ABSTRACT}

This paper first provides an overview of a series of experimental studies carried out at Carleton University over the past two decades on reinforced concrete (RC) shear walls strengthened or repaired with carbon fibre-reinforced polymer (CFRP) sheets. These studies have led to several unique contributions including the development of a novel tube anchor system, which improves the load transfer mechanism between the CFRP and RC supporting structural elements. The paper then presents a new finite element modelling technique to analyze CFRP strengthened RC shear walls with the newly developed tube anchor system. Two different modelling approaches are proposed to consider the effects of the tube anchor system. Additionally, a number of other important CFRP- and RC-related mechanisms including CFRP debonding effects, tension stiffening, compression softening, and strength and stiffness degradation under cyclic loads are also considered in the model. By comparing the analytical and experimental results, it is demonstrated that the proposed modelling approach can accurately replicate the observed complex behaviour of a wide range of CFRP-strengthened shear walls without requiring detailed 3D finite element (FE) modelling of the anchor system. 


\section{ACKNOWLEDGEMENTS}

I would like to thank the following people who have helped me accomplish this thesis:

My supervisor Professor David Lau, for his knowledgeable insight, encouragement and continuous support;

My co-supervisor Professor Vahid Sadeghian for his expert guidance, constant support and patience;

The Government of Ontario and Carleton University for their financial support;

Professor Jeffrey Erochko, who helped me greatly throughout my graduate studies;

Dear friends: Joshua Woods, Ahmed Hassan and Ibrahim Shaheen;

My parents, sisters and brothers, for their unwavering support.

Special thanks to my spouse and daughter, for their love and patience. 


\section{TABLE OF CONTENTS}

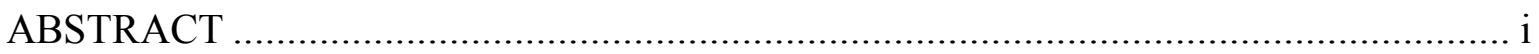

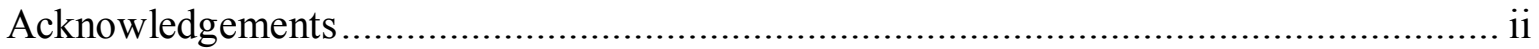

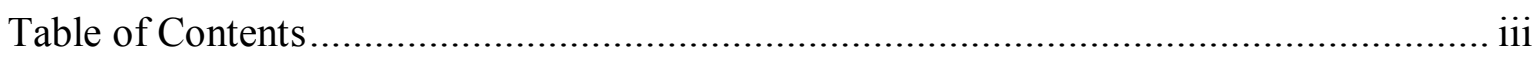

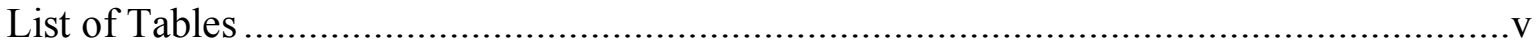

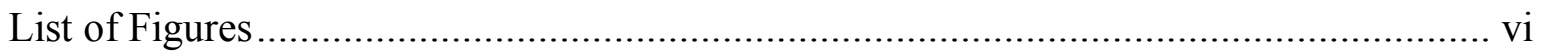

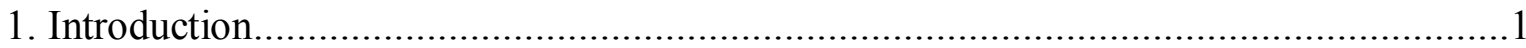

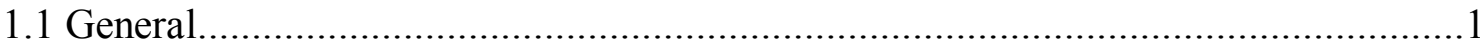

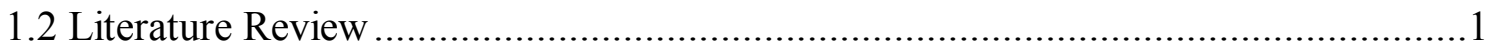

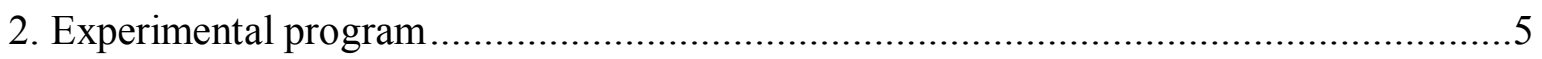

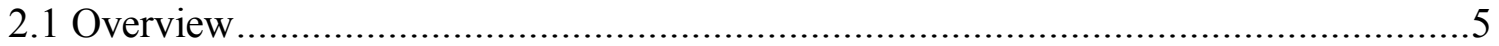

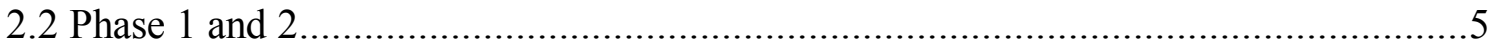

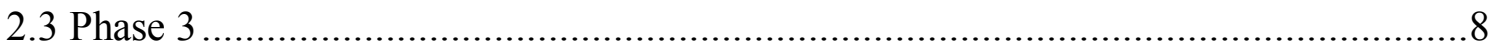

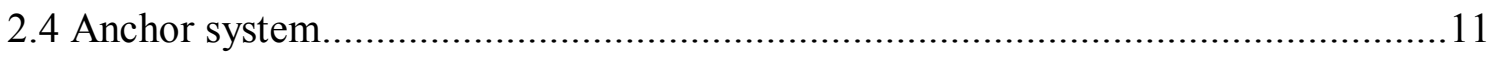

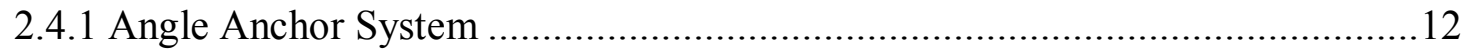

2.4.2 Tube Anchor System ..............................................................................13

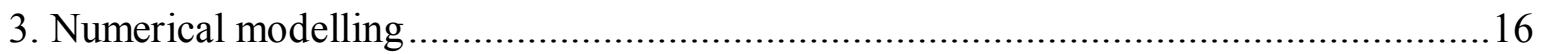

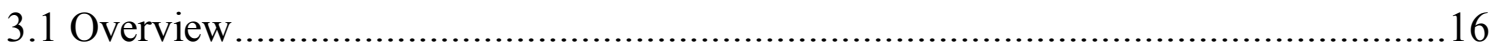

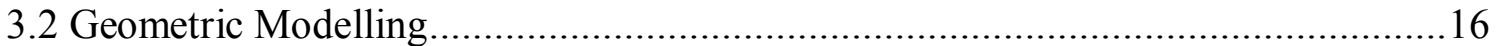

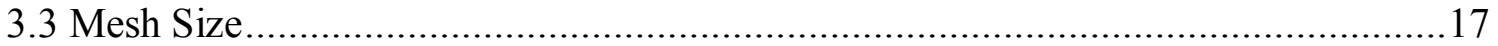




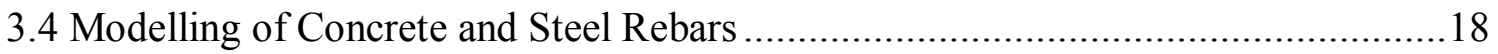

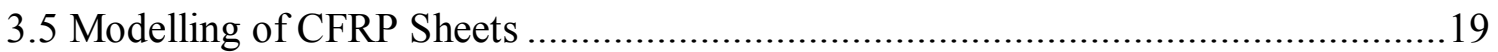

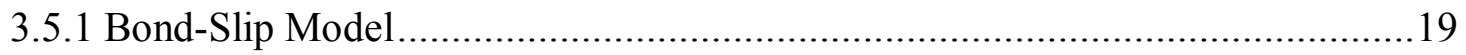

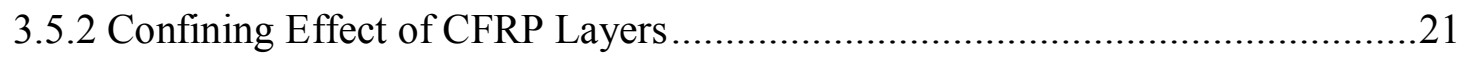

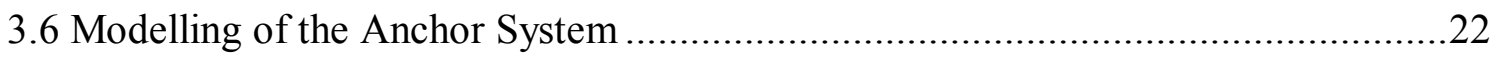

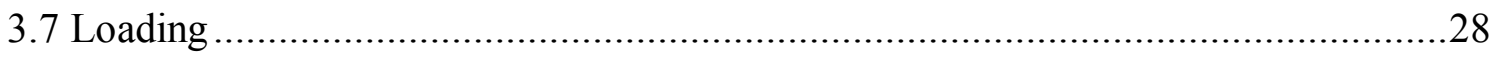

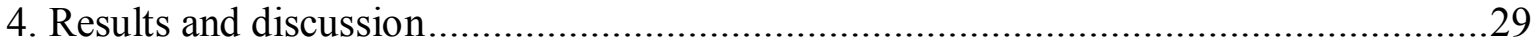

4.1 Significance of Considering the Anchor System ………....................................29

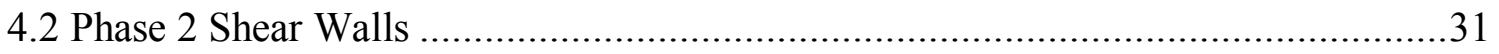

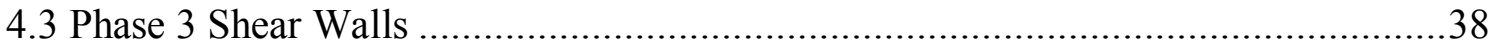

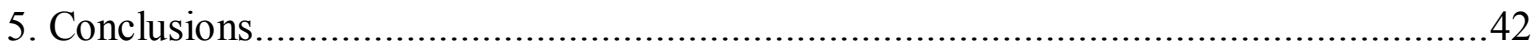

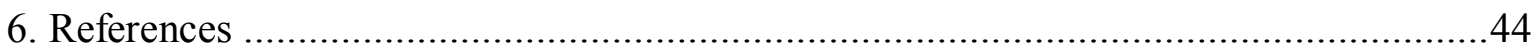

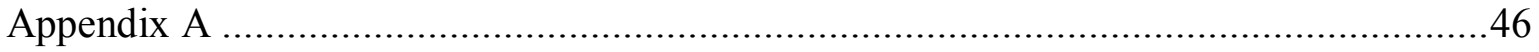

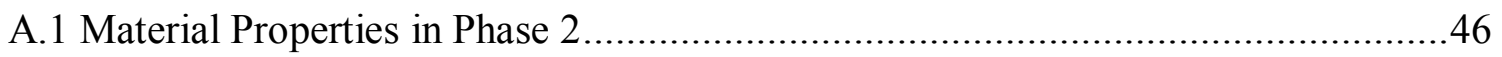

A.2 Steel Reinforcement in the Wall Specimens in Phase 2 ........................................47

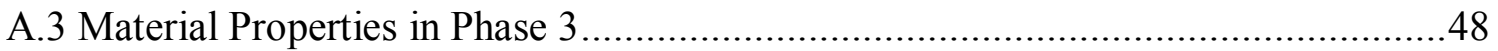

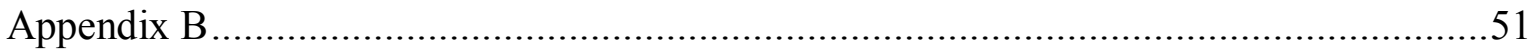




\section{LIST OF TABLES}

$1 \quad$ Strengthening and Repair Schemes in Phase 1 and 2 .................................. 7

2 Shear Wall Specimens' characteristics in Phase 3 (Woods 2018) ......................9

3 Computed against measured peak loads (Phase 2) ........................................33

$4 \quad$ Computed against measured sequence of failure (Phase 2) .............................33

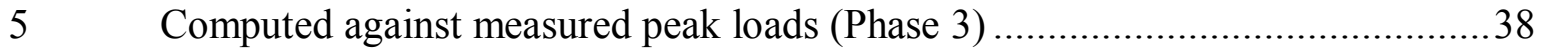

6 Computed against measured sequence of failure (Phase 3) .............................40

A.1.1 Concrete cylinder test results (from Hiotakis 2004) ...................................46

A.1.2 FRP sheets characteristics (from Hiotakis 2004) .........................................47

A.3.1 Steel reinforcement material properties (from Woods 2018) ..........................48

A.3.2 Concrete and CFRP material properties (from Woods 2018) ...........................49 


\section{LIST OF FIGURES}

$1 \quad$ Design details of shear walls in Phase 1 and 2 .6

2 Envelopes of hysteretic responses for control (CW), repaired (RW) and strengthened (SW) shear wall specimens in phase 1 and 2 ...........................

3 Envelopes of hysteretic responses for control (CW), repaired (RW) and

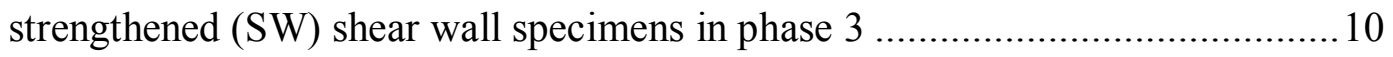

$4 \quad$ Steel angle anchor failure progression (Lau and Woods 2017)........................ 13

$5 \quad$ Forces acting on the tube anchor system .14

6 Envelopes of hysteretic response of shear walls with angle and tube anchor systems

$7 \quad$ Mesh sensitivity analysis 17

$8 \quad$ Material models used for concrete (left) and reinforcement (right) .18

9 Schematic of interface element and tri-linear bond stress-slip relationship .21

10 Sources of influences of anchor system: pulley mechanism and tube anchor flexibility .23

11 (a) First approach using link elements; (b) Second approach using springs .24

12 Modelling a small section of the development length .25

13 Force-displacement conversion to bond-slip and stress-strain relationships .......25

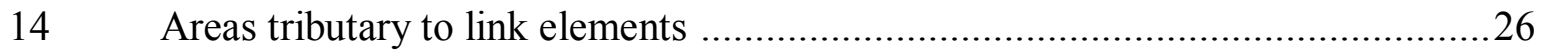

15 Finding deflection in one span of the tube anchor .....................................27

16 Schematic of perfect and imperfect bonds in Case (a) and Case (b) ..................28

17 Computed responses of approach (1), Case (a) and Case (b) compared with the measured envelope (SW1-2) 
18 Stress distribution in the CFRP trusses at the Base of the Wall (SW1-2), (a) at the

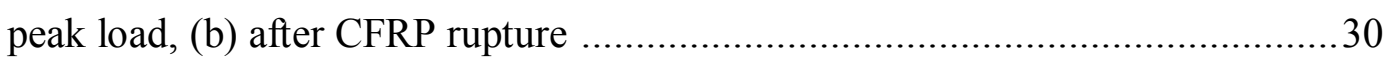

19 Observed and calculated responses of the control wall CW2 - phase 2 ............31

20 Observed and calculated responses of the strengthened shear walls in phase 2 using first and second approaches ............................................................. 32

21 Observed and calculated sequence of failure in wall SW1-2 (phase 2) ..............34

22 The stress distribution in the vertical reinforcement in wall SW1-2 (Phase 2) at the

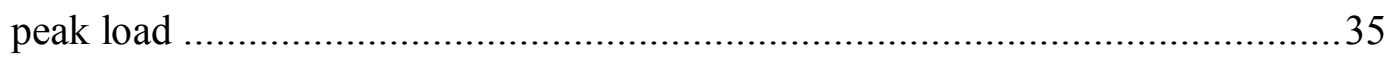

23 The stress distribution in the concrete in wall SW1-2 (Phase 2) at the peak load 36

24 The stress distribution in the FRP truss in wall SW1-2 (Phase 2) at the peak load

25 Observed and calculated responses of the control and strengthened shear walls in

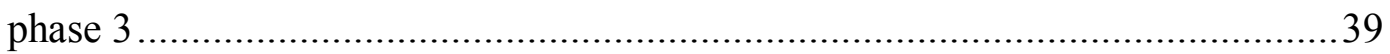

26 Failure modes in Phase 3 shear walls, (a) CW1 (b) CW2 (c) SW1 (d) SW2a ....41

A.1.1 Stress-Strain curve for No.10 steel rebars (from Hiotakis 2004) ......................46

A.2.1 Side view of the specimens' steel reinforcement (from Hiotakis 2004) .............47

A.2.2 Front view of the specimens' steel reinforcement (from Hiotakis 2004) ............48

A.3.2 Steel reinforcement detailing in Phase 3 wall specimens: (a) series 1; (b) series 2; (c) series

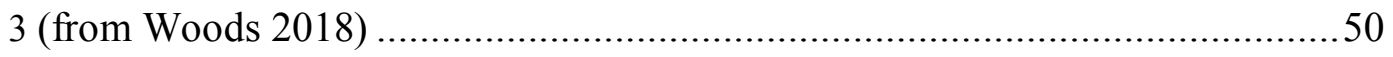

B.1 Finding the equivalent OOP reinforcement ratio ........................................51 


\section{INTRODUCTION}

\subsection{General}

Reinforced concrete (RC) shear walls are commonly used as a lateral load resisting system in structures constructed in earthquake-prone areas. Despite the fact that the modern practices of design and construction of shear walls have been greatly improved in recent decades, many older shear wall buildings are still found to be vulnerable and can suffer severe damage during moderate and large earthquakes due to insufficient in-plane stiffness, flexural and shear strengths, and/or ductility (Lombard et al. 2000). The use of fiber reinforced polymer (FRP) sheets is an attractive and least invasive option for repairing and strengthening shear walls in existing $\mathrm{RC}$ structures (Woods et al. 2016).

\subsection{Literature Review}

In recent years, many experimental and analytical studies have been conducted to examine the performance of carbon fibre reinforced polymer (CFRP) strengthened RC shear walls. Most of the experimental work focused on the shear strength and energy dissipation capacity of shear walls (Antoniades et al. 2003; Paterson and Mitchell 2003; Khalil and Gobarah 2005; Elnady 2008), while the number of experimental studies on flexural-critical shear walls strengthened with CFRP is comparatively less (Lombard et al. 2000; Hiotakis et al. 2004). To alleviate this relative lack of test data and to gain a better understanding of the observed behaviour, development of a reliable numerical model that can accurately predict the non-linear response of shear walls reinforced or repaired with CFRP sheets is critical. The numerical simulation model is necessary to determine whether the CFRP reinforced shear walls can achieve their intended performance targets under design level earthquakes. Whereas several researchers have developed numerical models for RC beams and slabs repaired/strengthened in flexure with CFRP (Teng et al. 2002; Wong and Vecchio 
2003; Oehler et al. 2003; Lu et al. 2007), little information exists on the analytical modelling of CFRP-strengthened RC shear walls. Recently, Woods et al. (2020) have tested CFRP reinforced shear walls by hybrid simulation, which involves combining computer models with physical test specimens. Cruz-Noguez et al. (2014) and Hassan et al. (2016) developed numerical models to compute the nonlinear response of deficient shear walls reinforced with CFRP sheets according to the Intermediate Crack (IC) Debonding model proposed by Lu et al. (2007). Vecchio and Bucci (1999) presented an FE simulation method for repairing/strengthening concrete structures that includes activating and inactivating elements in a structure. While this simulation method has been validated with 2D numerical modelling and analysis of RC beams and slabs strengthened with FRP sheets and RC shear walls repaired with concrete replacement, the assumption of perfect bonds between FRP and concrete in this model renders it not able to capture the crucial debonding behaviour of FRP and its impact on the post-peak response behaviour and ultimate performance. Cortes-Puentes and Palermo (2012) introduced modelling procedures to reproduce the response of strengthened RC shear walls using steel plates and FRP sheets. The modelling strategy included development of constitutive bond-slip models for link elements to simulate the anchorage of FRP sheets to concrete foundations.

In modelling CFRP strengthened walls, generally, the effects of anchor system are neglected because of its high rigidity and stiffness relative to the rest of the wall. While this simplified assumption may be acceptable for walls with conventional anchor systems, for walls with new anchor systems (e.g. the tube anchor system, described later on) the deformation and flexibility resulting from anchoring CFRP at the base need to be considered because of their significant influence on the ultimate behaviour of the strengthened walls. The new anchor systems allow CFRP sheets to develop their full tensile capacity without any premature failure at the base, 
significantly improving the strength and ductility of the strengthened wall. At such high stress levels, even small deformations in the anchor system can release a considerable amount of energy from the system and therefore affect the structural response of the wall. One approach to consider these effects is to include every detail of the anchor system in the FE model. However, micromodelling approach is computationally expensive and not practical for design applications. Thus, there is a need for an alternative modelling approach, which can accurately account for the effects of anchor systems in a practical manner with reasonable size of the modelling problem in terms of number of elements and mesh sizes.

Aiming to present an overview of the seismic performance of CFRP strengthened/repaired RC shear walls, this paper first provides a general summary of the series of experimental investigations on CFRP repaired/strengthened RC shear walls conducted at Carleton University, which will serve as the basis for the development of the numerical models in the present study. One of the main outcomes of this experimental campaign was the development of a novel tube anchor system, which eliminates the deficiencies found in conventional anchoring methods. Although the effectiveness of the new anchor system has been proven by the experimental investigations, there has not been numerical models that can be used to conduct analytical studies to help with parametric evaluation and design of the new anchor system and its influence on the response of CFRP strengthened shear walls to date. This paper presents a new finite element (FE) modelling approach, which considers the effects of the anchor system with good accuracy requiring no detailed micro modelling of the anchor system. Two analytical modelling approaches are presented and discussed in detail. The analytical results were compared with measured experimental data and good agreement was observed for main structural response parameters. Taking into account the influence of the anchor system in the analytical model, deemed to be 
critical for accurate and reliable simulation of the seismic behaviour and performance of shear walls reinforced with CFRP sheets. 


\section{EXPERIMENTAL PROGRAM}

\subsection{Overview}

A comprehensive three-phase experimental program was conducted at Carleton University to investigate the seismic performance of CFRP strengthened/repaired RC shear walls. The influences of different key parameters including the anchor type, aspect ratio, repair and strengthening scheme, presence of initial damage, and failure mode were explored in the experimental research program. The shear walls were subjected to a quasi-static reversed cyclic loading condition in the horizontal direction to represent earthquake loading effects; the wall specimens were not subjected to axial loads to allow for comparison with future studies taking into account the effect of axial load. Different from other studies, shear wall specimens were reinforced with CFRP sheets rather than CFRP wraps as a more convenient and representative repair or strengthening technique employed in the field, where easy access for wrapping of FRP sheets around shear walls is difficult or impossible. The results of the experimental program were used to validate the analytical model developed in this paper. Below, a brief overview of each phase of the experimental program is presented.

\subsection{Phase 1 and 2}

The first two phases of the experimental program examined the behaviour of flexural-critical RC shear walls retrofitted with CFRP sheets. In these two phases, the wall specimens were designed according to modern design standards (CSA A23.3-94). The key difference between the two phases was the type of anchor used to transfer the force from the CFRP sheets to the supporting foundation block. In the first phase of the experimental program carried out by Lombard et al. (2000), steel angles were used as the anchor for the CFRP sheets. The second phase of the 
experimental program examined the efficiency of a new type of anchor system called tube anchor system (Hiotakis 2004; Cruz-Noguez et al. 2014b).

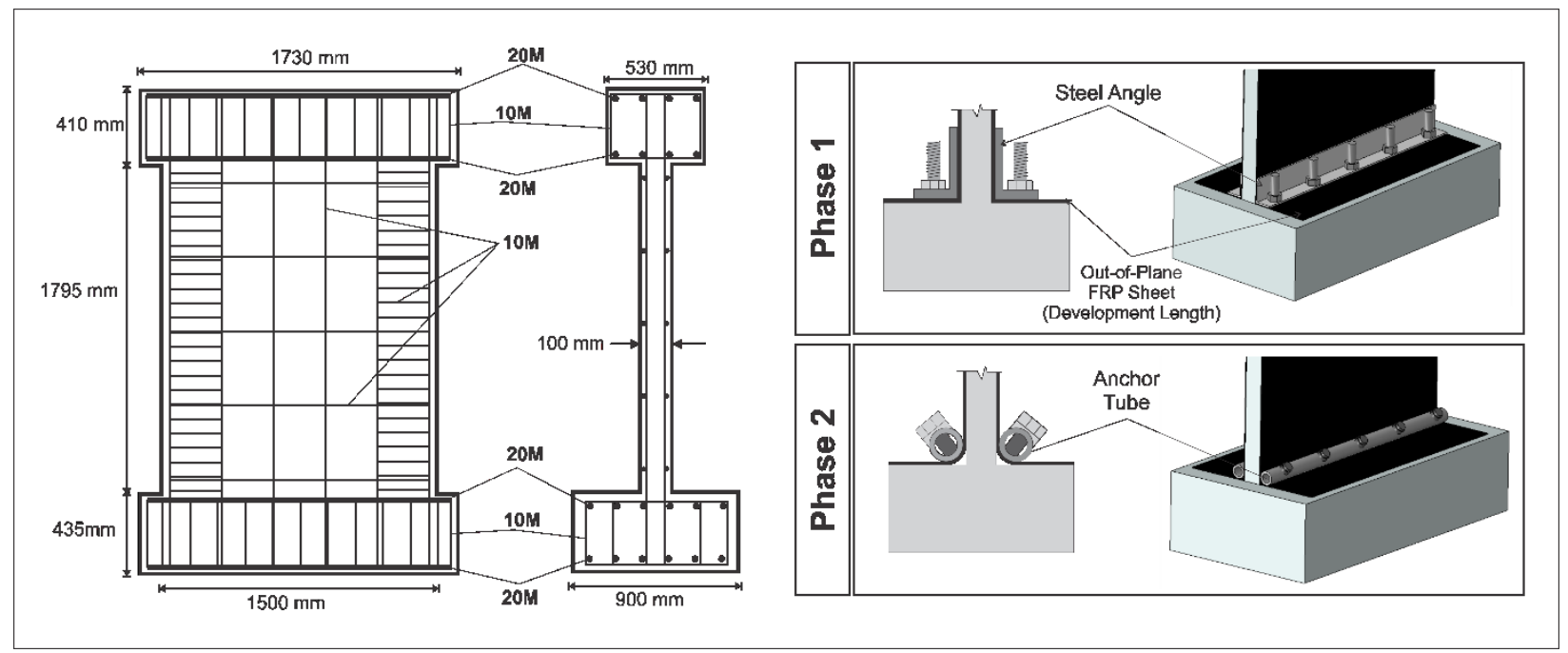

Fig. 1. Design details of shear walls in Phase 1 and 2

More details about the two anchor systems are presented later in this report. The height-towidth aspect ratio of the wall specimens tested in Phase 1 and 2 was 1.2. Along with the type of anchor system, other test parameters were: the existence of initial damage prior to repair and strengthening; and variation in the strengthening scheme in which both vertical and horizontal CFRP sheets were used. Fig. 1 shows specimen dimensions, reinforcement details, and the two anchor systems used in Phase 1 and 2 of the experimental program. Additional information of the concrete, steel reinforcement and FRP materials, and steel reinforcement distribution of Phase 2 wall specimens are provided in Appendix A. The strengthening and repair schemes implemented in these phases are listed in Table 1. Fig.2 shows the envelopes of the hysteretic responses obtained from the two phases of the experimental study.

Later, Cruz-Noguez et al. (2014b) studied in detail the results of the experimental work carried out by Lombard et al. (2000) and Hiotakis (2004), making thorough comparisons between 
TABLE 1. Strengthening and repair schemes in Phase 1 and 2

\begin{tabular}{ccccccc}
\hline Phase & $\begin{array}{c}\text { Anchor } \\
\text { Type }\end{array}$ & Failure mode & $\begin{array}{c}\text { Aspect } \\
\text { Ratio }^{\mathrm{a}}\end{array}$ & $\begin{array}{c}\text { Type of } \\
\text { Specimen }\end{array}$ & $\begin{array}{c}\text { Repair/Strengthening } \\
\text { Scheme }^{\mathrm{b}}\end{array}$ & Wall I.D. \\
\hline 1 & Angle & Flexural & 1.2 & Control & --- & CW1 \\
& Dominant & 1.2 & Repaired & $1 \mathrm{~V}$ & RW1 \\
& & 1.2 & Strengthened & $1 \mathrm{~V}$ & SW1-1 \\
& & 1.2 & Strengthened & $2 \mathrm{~V}+1 \mathrm{H}$ & SW2-1 \\
& \multirow{3}{*}{ Tube } & & 1.2 & Control & --- & CW2 \\
& & 1.2 & Repaired & $1 \mathrm{~V}$ & RW2 \\
& & 1.2 & Strengthened & $1 \mathrm{~V}$ & SW1-2 \\
& & 1.2 & Strengthened & $2 \mathrm{~V}$ & SW2-2 \\
& & 1.2 & Strengthened & $3 \mathrm{~V}+1 \mathrm{H}$ & SW3-2 \\
\hline
\end{tabular}

${ }^{a}$ Aspect Ratio: height to length ratio $\left(\mathrm{h}_{\mathrm{w}} / \mathrm{l}_{\mathrm{w}}\right)$

${ }^{b}$ V-Vertically oriented CFRP sheets and H-Horizontally oriented CFRP sheets
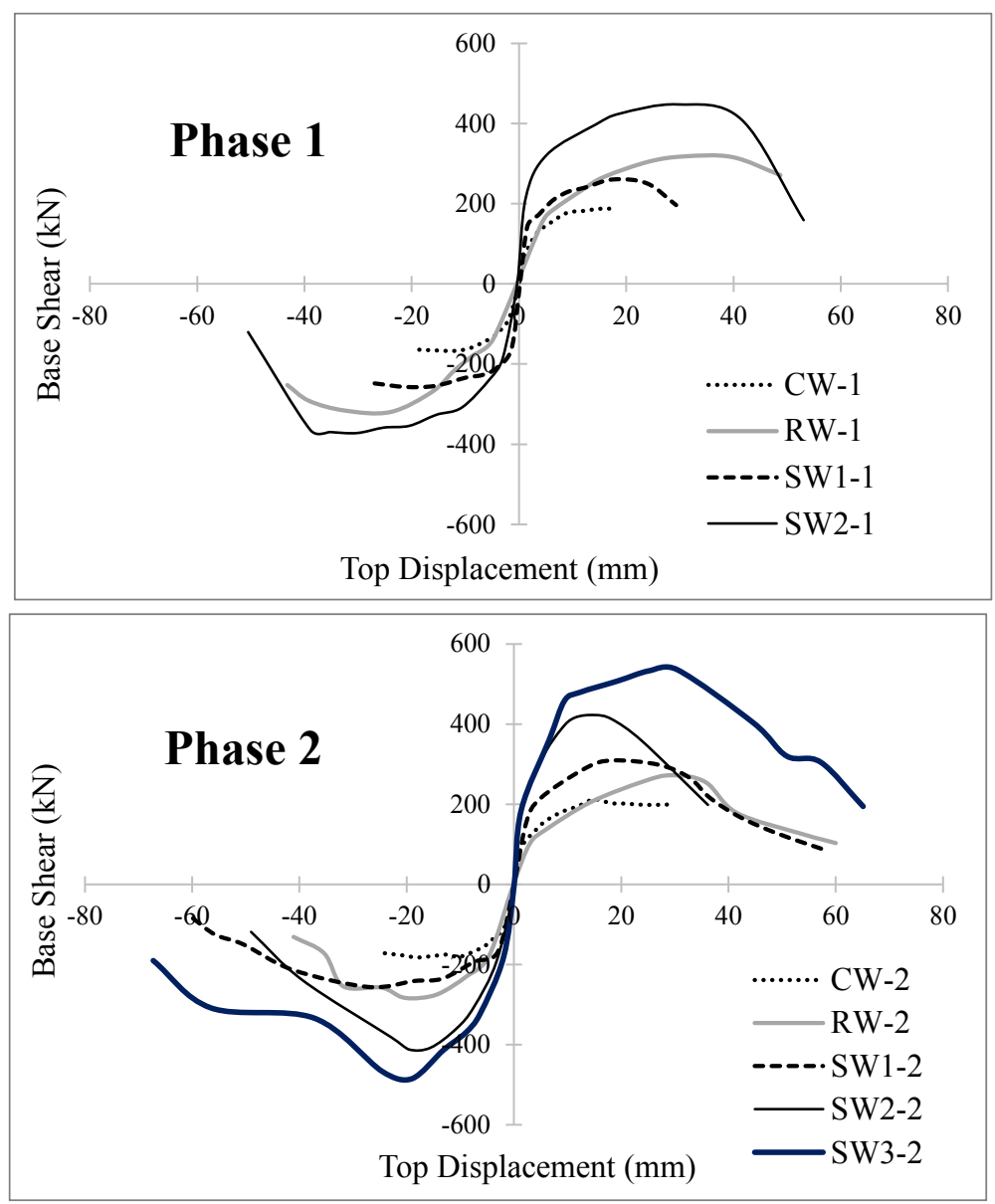

Fig. 2. Envelopes of hysteretic responses for control (CW), repaired (RW) and strengthened (SW) shear wall specimens in phase 1 and 2 
the observed failure mechanisms, CFRP-concrete debonding progressions, and features of forcedeformation response (e.g. peak strength, ductility, energy dissipation, pinching effect etc.). The study concluded that in repair applications, the CFRP retrofitting system was able to regain most of the initial elastic stiffness and enhance the flexural capacity of the damaged walls. In strengthening applications (i.e. walls in as-built conditions), there was a significant increase in the stiffness and flexural capacity of the walls (Woods 2018). Furthermore, it was found that using the new tube anchor system greatly improved the structural performance of shear walls. A detailed discussion on the behaviour of the two anchor systems used for the shear walls is provided later in the paper.

\subsection{Phase 3}

Nine RC shear wall specimens were tested under in-plane reversed cyclic loads in Phase 3. In addition to the same 1.2 aspect ratio of the test walls used in earlier phases of the experimental program, Phase 3 also included shear walls with lower aspect ratios of 0.85 and 0.65 , as typical representatives of older nonductile shear walls susceptible to brittle shear failure in existing buildings. The shear walls in Phase 3, with common structural deficiencies including insufficient shear reinforcement and poor confinement of the boundary elements, were designed according to older design standards, specifically CSA A23.3-77. An optimized version of the tube anchor was used in series 1 and 2 of the test program. Since there were no vertical CFRP layers in the series 3 and 4 wall specimens, anchorage of the vertical CFRP sheets was not required. Two of the nine shear wall specimens had an aspect ratio equal to the walls tested by Lombard et al. (2000) and Hiotakis (2004) $\left(h_{w} / l_{w}=1.2\right)$ to correlate the efficiency of different CFRP retrofitting systems employed in different phases of the study. Information of the concrete, steel reinforcement and FRP materials, and steel reinforcement distribution of Phase 3 wall specimens are provided in 
Appendix A. The results of these experiments were originally presented in Woods (2014). Table 2 lists the characteristics of the shear wall specimens in Phase 3 of the experimental program. In strengthening applications, the retrofitted structural system was capable of enhancing the in-plane load resisting capacity, ductility, and energy dissipation capacity; in repair applications, the retrofitted system was able to regain the wall specimen's original state (Woods 2018), as can be seen in Fig. 3.

TABLE 2. Shear wall specimens' characteristics in Phase 3 (Woods 2018)

\begin{tabular}{cccccccccc}
\hline Series & $\begin{array}{c}\text { Physical } \\
\text { Specimen }\end{array}$ & $\begin{array}{c}\text { Wall } \\
\text { I.D. }\end{array}$ & $\begin{array}{c}\text { Type of } \\
\text { Specimen }\end{array}$ & $\begin{array}{c}\text { Aspect } \\
\left(\mathrm{l}_{\left.\mathrm{w} . \mathrm{t}_{\mathrm{w}}\right)}(\mathrm{mm})\right.\end{array}$ & $\begin{array}{c}\text { Ratio } \\
\left(\mathrm{h}_{\mathrm{w}} / \mathrm{l}_{\mathrm{w}}\right)\end{array}$ & $\begin{array}{c}\rho_{\mathrm{v}} \\
(\%)\end{array}$ & $\begin{array}{c}\rho_{\mathrm{h}} \\
(\%)\end{array}$ & $\begin{array}{c}\text { Vertical } \\
\text { CFRP } \\
\text { Sheets }^{\mathrm{a}}\end{array}$ & $\begin{array}{c}\text { Horizontal } \\
\text { CFRP } \\
\text { Sheets }^{\mathrm{b}}\end{array}$ \\
\hline 1 & 1 & CW1 & Control & $1500 \times 100$ & 1.2 & 3.0 & 0.25 & - & - \\
& 1 & RW1 & Repaired & $1500 \times 100$ & 1.2 & 3.0 & 0.25 & 2 & 6 \\
& 2 & SW1 & Strengthened & $1500 \times 100$ & 1.2 & 3.0 & 0.25 & 2 & 6 \\
& 3 & CW2 & Control & $2100 \times 140$ & 0.85 & 3.0 & 0.25 & - & - \\
& 3 & RW2 & Repaired & $2100 \times 140$ & 0.85 & 3.0 & 0.25 & 2 & 6 \\
& 4 & SW2a & Strengthened & $2100 \times 140$ & 0.85 & 3.0 & 0.25 & 2 & 6 \\
& 5 & SW2b & Strengthened & $2100 \times 140$ & 0.85 & 3.0 & 0.25 & 2 & 6 \\
& 6 & CW3 & Control & $2750 \times 180$ & 0.65 & 3.0 & 0.25 & - & - \\
& 6 & RW3 & Repaired & $2750 \times 180$ & 0.65 & 3.0 & 0.25 & 0 & 8 \\
& 7 & SW3 & Strengthened & $2750 \times 180$ & 0.65 & 3.0 & 0.25 & 0 & 8 \\
& 8 & SW4a & Control & $2750 \times 180$ & 0.65 & 3.0 & 0.25 & - & - \\
& 8 & RW4a & Repaired & $2750 \times 180$ & 0.65 & 3.0 & 0.25 & 0 & 8 \\
& 9 & CW4b & Control & $2750 \times 180$ & 0.65 & 3.0 & 0.25 & - & - \\
& 9 & RW4b & Repaired & $2750 \times 180$ & 0.65 & 3.0 & 0.25 & 0 & 8 \\
\hline
\end{tabular}

${ }^{a, b}$ Total number of vertical and horizontal CFRP layers on both sides of the specimen

${ }^{c}$ Specimen SW2b has all of the layers of CFRP applied to a single side of the wall 
(a)

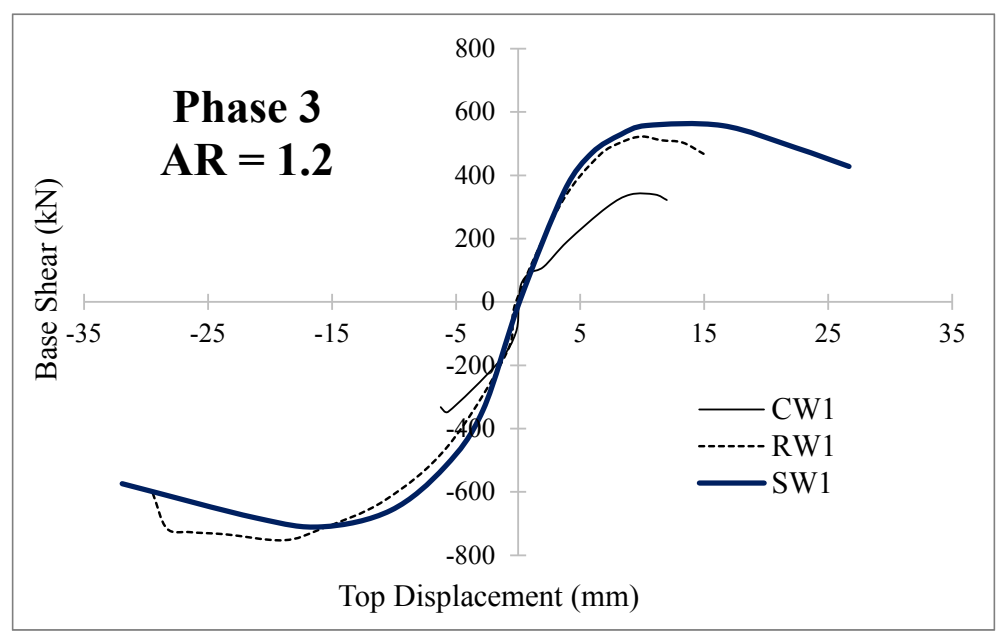

(b)
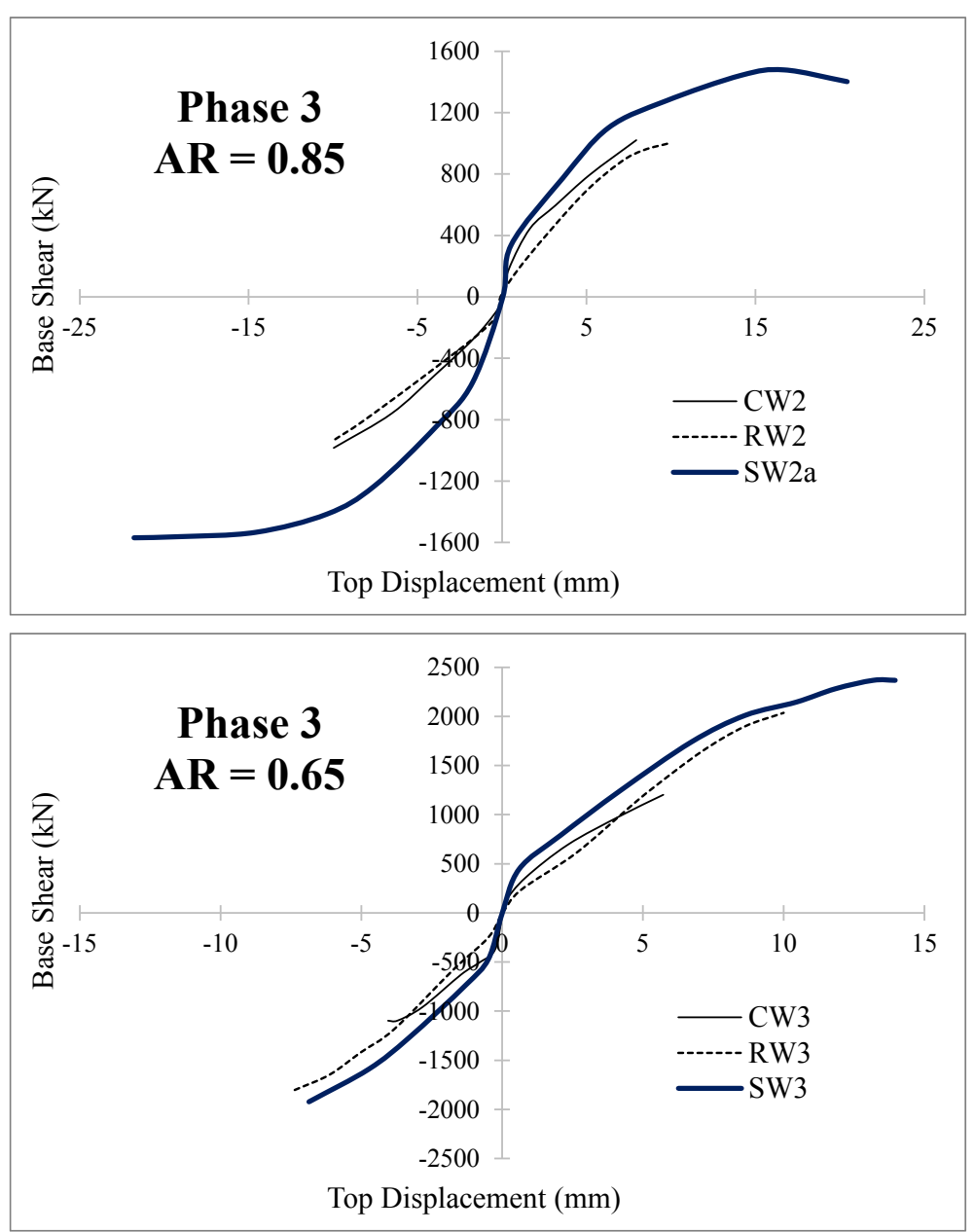

Fig. 3. Envelopes of hysteretic responses for control (CW), repaired (RW) and strengthened (SW) shear wall specimens in phase 3, (a) $\mathrm{AR}=1.2$, (b) $\mathrm{AR}=0.85$, (c) $\mathrm{AR}=0.65$ 


\subsection{Anchor system}

The purpose of the anchor system is to facilitate the transfer of the load carried by the CFRP to the adjacent structural members. In strengthening or repair applications, where externally bonded CFRP sheets are employed, the failure is commonly governed by crushing of concrete and/or rupture of CFRP sheets, after yielding of the steel reinforcement (Grelle and Sneed 2011; Hassan and Lau 2016). In the experimental investigations carried out at Carleton, however, it was found that after the CFRP sheets debonded from the concrete substrate, they prematurely ruptured prior to reaching their ultimate tensile capacity (see Fig. 4). This was mainly due to the poor performance of the conventional L-shaped steel angle anchor system, preventing the member from reaching its maximum design strength (Lombard et al. 2000; Teng et al. 2002; Cruz-Noguez et al. 2014). Failure of the CFRP to develop its ultimate tensile capacity before failure of the shear wall reduces the efficient use of the CFRP materials in resisting seismic loads. To help CFRP reaching its ultimate tensile capacity and minimize CFRP-concrete debonding, various CFRP anchor systems have been developed. Several studies on CFRP-strengthened RC beams and slabs confirm that employing effective anchorage systems can enhance the overall performance of structural elements (Triantafillou 1998; Smith and Teng 2003). Studies on RC shear walls by Lombard et al. (2000), Hiotakis (2004), and El-Sokkary et al. (2013), likewise, determined that CFRP anchor has a significant effect on preventing premature debonding failures.

In anchoring of the vertical CFRP sheet on a shear wall, the tension force carried by the vertical CFRP sheet should be equal to the tension in the out-of-plane (OOP) portion of the CFRP sheet attached to the horizontal surface of the supporting floor or foundation, which in turn must be provided by appropriate development length. According to the ACI440.2R-08 (ACI Committee 2002) guideline which provides guidance for the design and application of externally bonded 
CFRP systems, a minimum length of the CFRP sheet must be bonded to the concrete element $\left(1_{\mathrm{df}}\right)$, as determined by (Eq. 1):

$$
l_{d f}=\sqrt{\frac{n_{s} E_{f} t_{s}}{\sqrt{f_{c}^{\prime}}}}
$$

where $n_{s}$ is the number of CFRP sheets needing development, $E_{f}$ is the modulus of elasticity of the CFRP composite, $t_{s}$ is the thickness of the CFRP sheet and $\mathrm{f}_{\mathrm{c}}$ is the uniaxial compressive strength of the concrete in contact with the CFRP. The development length used in the experimental program is $350 \mathrm{~mm}$, which is very conservative compared to the minimum length obtained by using (Eq. 1).

Various CFRP-concrete debonding mechanisms and the two anchor systems utilized in the experimental studies carried out at Carleton are briefly discussed in the following sections.

\subsubsection{Angle Anchor System}

Steel angle anchor system is one of the most familiar mechanical anchor systems. Lombard et al. (2000) and Kanakubo et al. (2000) observed debonding of the CFRP material from the concrete wall, assisted by the steel angle anchor system, before the CFRP material reaching its ultimate capacity. Among the main deficiencies of the angle anchor system is the rotation and failure of the steel anchor, also known as "prying" action, caused by a moment due to the eccentricity between the tensile force in the CFRP sheet and the reactions of the anchoring bolts as shown in Fig.4(a) and Fig.4(b). The prying action during cyclic response of the shear wall results in debonding when the flange moves off from the surface of the wall as illustrated in Fig.4(c). When the direction of the load changes, the debonded CFRP sheet folds, which results in fracture of the hardened epoxy matrix. The sharp edges made by the fractured CFRP sheet, cut the CFRP 
fibres before reaching the ultimate rupture capacity. This behaviour reduces the load resisting capacity of the CFRP sheet (Lau and Woods 2017).

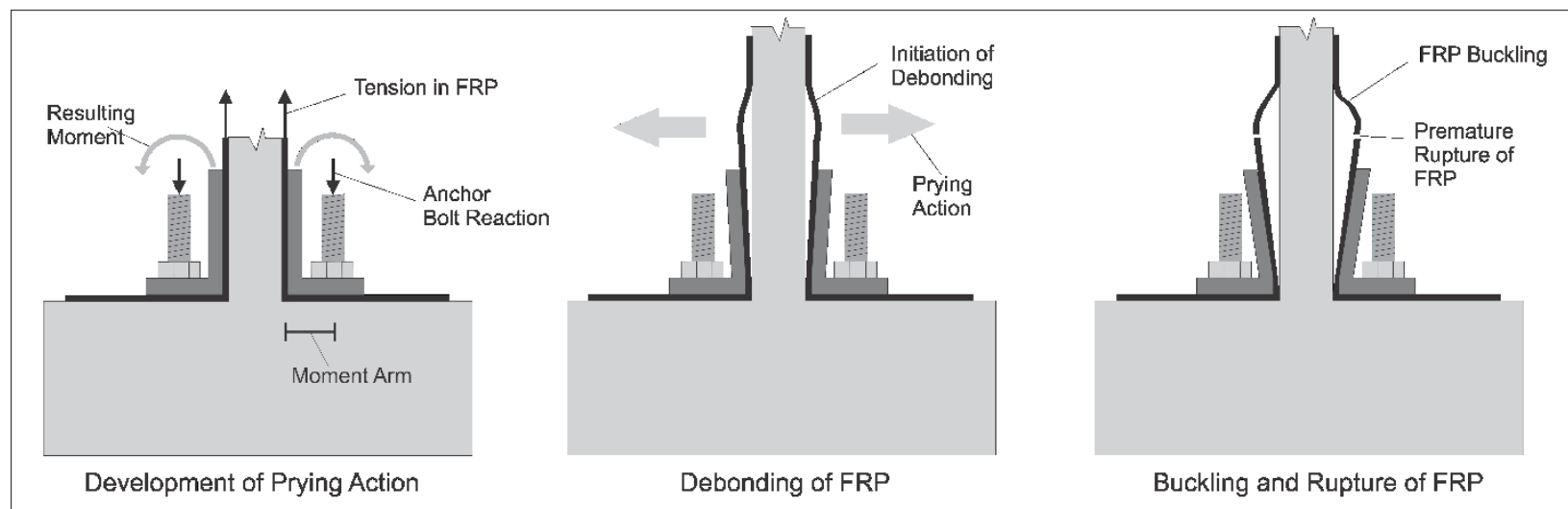

(a)

(b)

(c)

Fig. 4. Steel angle anchor failure progression (Lau and Woods 2017)

\subsubsection{Tube Anchor System}

As mentioned earlier, to eliminate the prying action of the conventional steel angle anchor that results in premature debonding of the CFRP material from the concrete substrate, a novel tube anchor system was designed utilizing a cylindrical hollow section (CHS). For a tube anchor, the CFRP sheet is wrapped around the tube and attached to the adjacent members. The tube is anchored to the wall foundation using several threaded steel anchor rods at a 45 -degree angle. The pulley principle is utilized in the design of the tube anchor. When the CFRP sheet is subjected to tension load, the force in the vertical CFRP sheet is equal to the force in the out-of-plane (OOP) CFRP sheet, which must have sufficient development length to transfer an equal force to the horizontal surface of the foundation block, as shown in Fig. 5. The eccentricity between the forces carried by the CFRP sheets and the anchor bolts is eliminated by placing the anchor bolts in the direction of the resultant load. Experimental results and observations by Hiotakis (2004) and Cruz-Noguez et 
al. (2014) confirmed that the anchor system is effective in transferring the load to the adjacent structural member.

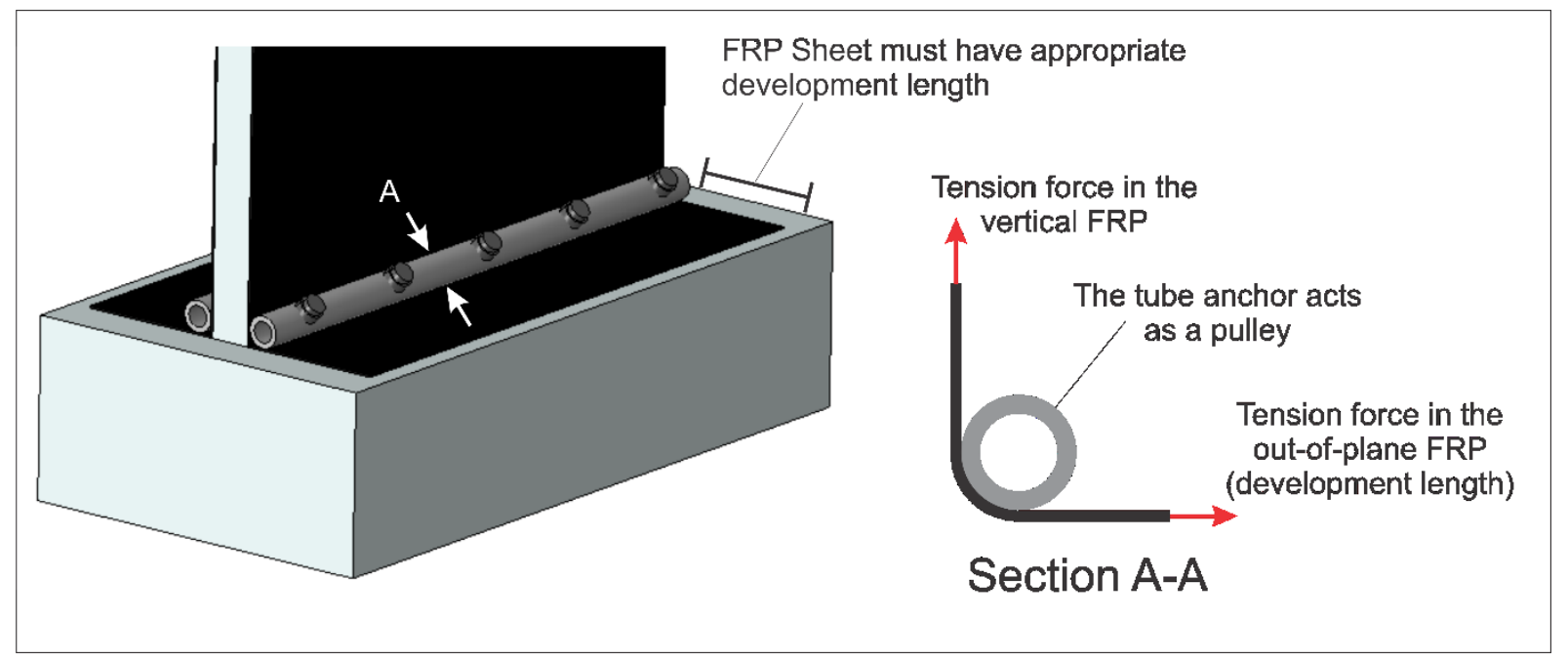

Fig. 5. Forces acting on the tube anchor system

Improvement in efficiency can be observed in Fig. 6, which compares the hysteretic response envelopes of two wall specimens having identical properties in terms of steel and CFRP reinforcement, but different anchor systems. The wall with steel angle anchor (SW1-1) was selected from Phase 1 of the experimental studies, while the wall with the tube anchor (SW1-2) was part of the Phase 2 of the tests. Using tube anchor system improves considerably the strength, ductility and energy dissipation capacity of CFRP retrofitted RC shear walls compared to identical walls with angle anchor system. 


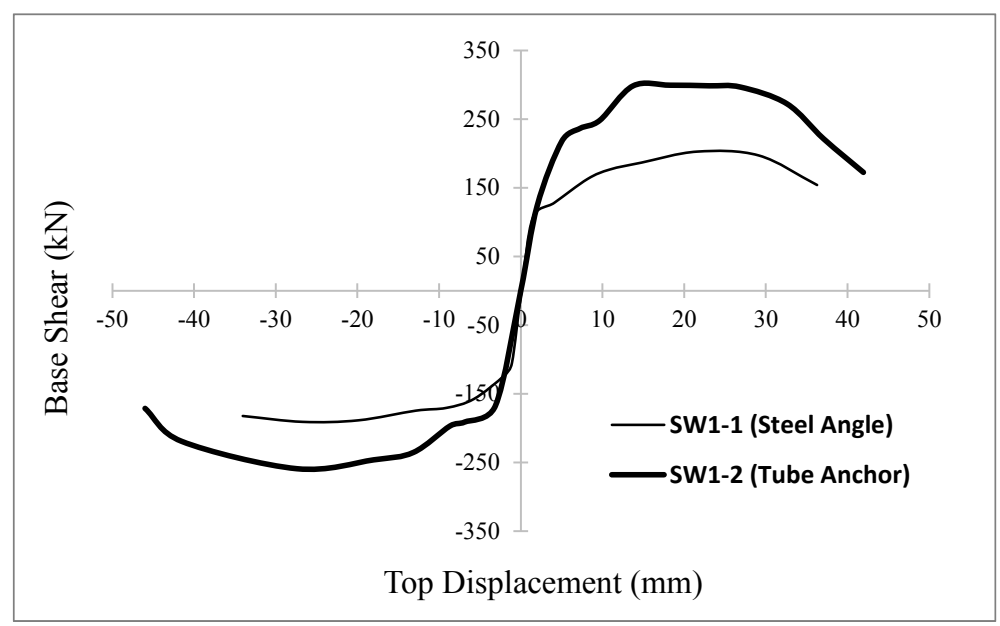

Fig. 6. Envelopes of hysteretic response of shear walls with angle and tube anchor systems 


\section{NUMERICAL MODELLING}

\subsection{Overview}

In this study, a finite element (FE) modelling technique was developed for CFRPstrengthened RC shear walls that takes into consideration the effect of anchor system on the structural response without requiring detailed micro modelling of the anchor system. The FE models were developed using VecTor2, a 2D nonlinear analysis program specially developed for reinforced concrete structures. VecTor2 is based on the Modified Compression Field Theory (MCFT) (Vecchio and Collins 1986), and the Disturbed Stress Field Model (DSFM) (Vecchio 2000). The DSFM and MCFT are smeared rotating crack models where cracked concrete is represented as an orthotropic material using a secant stiffness-based formulation. While the formulation is presented in terms of average stresses and strains within a macro-modelling framework, special considerations are given to the condition of the concrete at the crack locations to improve the accuracy of the models. In the following sections, a brief description of the proposed modelling technique is presented.

\subsection{Geometric Modelling}

All wall specimens in Phase 1 and 2 have height-to-length aspect ratio (AR) of 1.2; however, in Phase 3 the wall specimens have three different ARs: 1.2, 0.85 and 0.65 . The control and strengthened walls in Phase 2 (CW2, SW1-2, SW2-2, SW3-2) and the control and strengthened walls in Phase 3 (CW1, CW2, CW3, SW1, SW2a, SW3) were selected to be modeled numerically. Concrete and vertical CFRP sheets were modeled using four-node rectangular elements and twonode truss elements, respectively. Vertical CFRP sheets are more prone to debonding because of their higher tensile stresses. To capture deboning and accurately represent the tension stiffening effect of vertical CFRP sheets they were modeled with truss elements. To improve the 
computational performance of the model and make it more efficient and practical in applications, the horizontal CFRP layers, which are less critical, are added as a smeared component to the underlying concrete elements. The geometry of Phase 2 wall specimens was divided into four zones: wall core, wall boundaries, cap beam and foundation block; whereas the wall specimens' geometry in Phase 3 was divided into three zones: wall core, cap beam and foundation block; as the walls in Phase 3 were designed according to old standards and hence, lack wall boundaries. The boundary condition at the bottom of the foundation block was assumed to be fully fixed. The interaction between concrete and CFRP layers was modeled by link elements which will be discussed later in the paper.

\subsection{Mesh Size}

Results from a mesh sensitivity analysis of the shear wall (SW1-2) confirmed that the maximum lateral force capacity computed by the finite element model with a mesh size of $50 \mathrm{~mm} \times 75 \mathrm{~mm}$ was within $2 \%$ of that of a different model with a smaller mesh size of $40 \mathrm{~mm} \times 60 \mathrm{~mm}$. As a result, a finite element model of mesh size $50 \mathrm{~mm} \times 75 \mathrm{~mm}$ was employed for accurate modelling of the shear wall while maintaining computational efficiency.

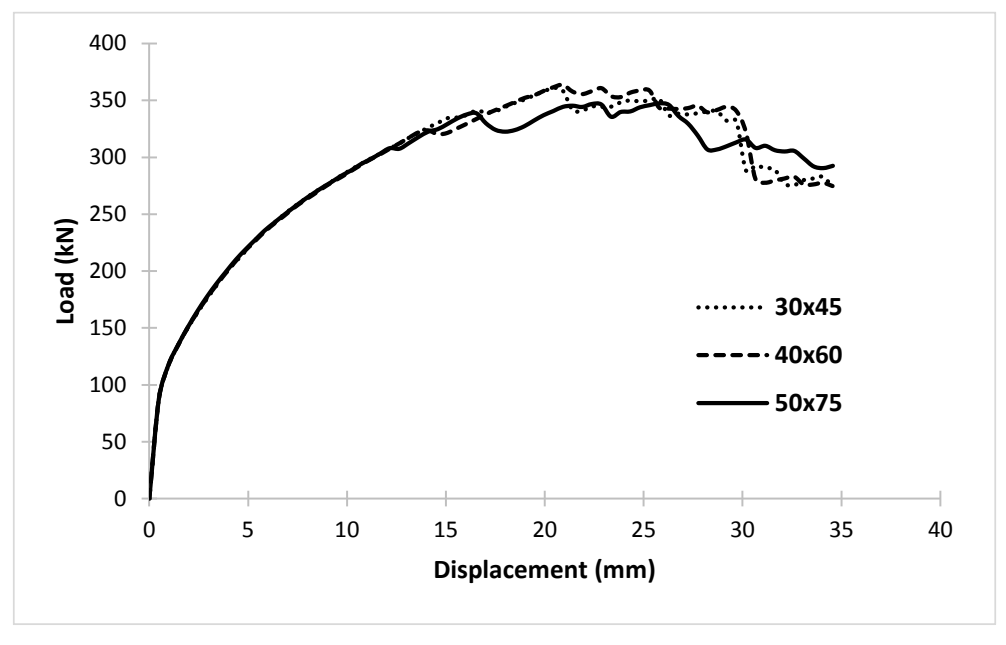

Fig. 7. Mesh sensitivity analysis 
Fig.7 shows the result of the mesh sensitivity study. Larger mesh sizes were used in the cap beam and the foundation block regions since the behaviour is nearly rigid in those regions and both concrete and steel behave in an elastic manner.

\subsection{Modelling of Concrete and Steel Rebars}

Several material constitutive models are adapted from the literature to account for important mechanisms influencing the response of concrete and reinforcement. The pre- and post-peak compressive responses of concrete were modeled according to the Popovics (NSC) and Popovics/Mander models (Wong et al. 2013), respectively. The compression softening behaviour of concrete was considered using the Vecchio's model (Wong et al. 2013). The tension stiffening and tension softening effects of reinforcement were computed with models developed by FieldBischoff (2004) and Hordjik (Wong et al. 2013), respectively, as shown in Fig. 8 (right). The hysteretic behaviour of concrete was taken into account by using a model proposed by Vecchio (1999) which follows a nonlinear unloading response for both tension and compression and is capable of computing plastic strains due to internal damage.
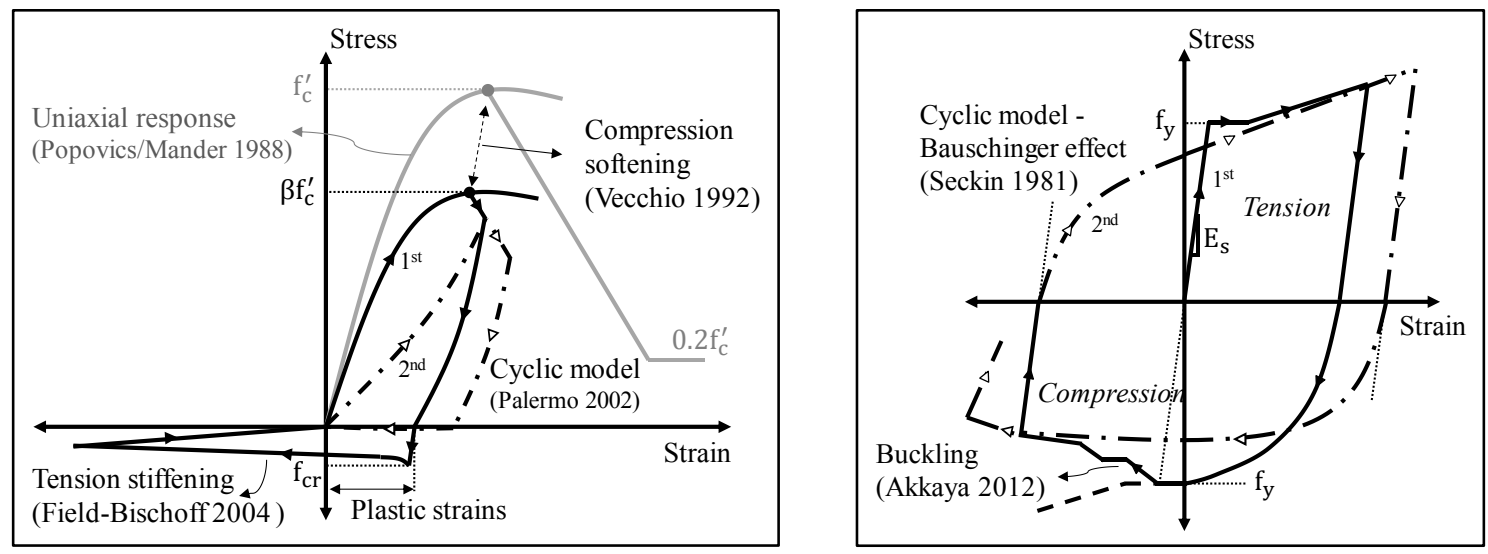

Fig. 8 - Material models used for concrete (left) and reinforcement (right)

The reinforcing bars in reinforced concrete were modeled as smeared reinforcement, as both horizontal and vertical reinforcements were distributed uniformly along the height and length of 
the wall. The hysteretic response of reinforcement was calculated using Seckin (1981) model which accounts for the Bauschinger effect (see fig. 8 (right). The Akkaya et al. (2012) model was employed to capture any potential buckling effects in the reinforcement under compression, as shown in Fig 8 (right).

\subsection{Modelling of CFRP Sheets}

The vertical CFRP sheets were modeled as discrete two-node truss elements of elastic, tension-only reinforcement; while the in-plane horizontal CFRP layers were modeled using smeared tension-only reinforcement. The area of the CFRP trusses was calculated based on the thickness, number of layers and tributary width of the CFRP sheets. The stress-strain relation in the CFRP material was assumed to behave linear elastically up until rupture in tension. The tension stiffening and crack control effects of CFPR are considered using Sato and Vecchio model (2003). The model computes the crack spacing and the contribution of CFRP to the tensile strength by formulating the equilibrium at the crack location based on the Tension Chord concept (Kaufmann and Marti, 1998).

\subsubsection{Bond-Slip Model}

Link elements were used at the interface of $\mathrm{RC}$ rectangular elements and CFRP truss elements to represent the bond-slip relationship between the CFRP and concrete. The link element is a two-node zero-length element with four translational degrees-of-freedom (DOFs). The interaction between the two nodes of a link element is represented by two springs: the "shear" spring, which acts along the longitudinal axis of the CFRP truss and the "normal" spring, which acts in the direction of the orthogonal axis, as illustrated in Fig.9. The shear spring was used to represent the bond-slip behaviour, while a very large stiffness value was assigned to the normal spring to prevent any movement in the orthogonal direction. The tri-linear approximation of the 
bond-slip model proposed by Lu et al. (2005) was employed in which the relation between shear stress and slippage is derived from CFRP-concrete pull tests. This Bond-slip relationship is defined by the following equations:

$$
\begin{aligned}
& \tau= \begin{cases}\tau_{\max } \sqrt{\frac{s}{s_{0}}} & \text { if } s \leq s_{0} \\
\tau_{\max } \cdot e^{-\alpha\left(\frac{s}{s_{0}}-1\right)} & \text { if } s>s_{0}\end{cases} \\
& \tau_{\max }=1.5 \beta_{w} f_{t} \\
& s_{0}=0.0195 \beta_{w} f_{t} \\
& \beta_{w}=\sqrt{\frac{2.25-\frac{b_{f}}{b_{c}}}{1.25+\frac{b_{f}}{b_{c}}}} \\
& \alpha=\frac{1}{\frac{G_{f}}{\tau_{\max } s_{0}}-\frac{2}{3}} \\
& G_{f}=0.308 \beta_{w}^{2} \sqrt{f_{t}}
\end{aligned}
$$

where $\tau=$ shear bond stress (MPa); $\mathrm{s}=$ interfacial slip (mm); $G_{f}=$ interfacial fracture energy $(\mathrm{MPa}) ; b_{f}=$ width of the strip of FRP laminate $(\mathrm{mm}) ; b_{c}=$ width of the concrete member $(\mathrm{mm})$; and $\beta_{w}=$ FRP to concrete width ratio. Based on the above equations, the maximum bond shear stress $\left(\tau_{\max }\right)$ was calculated to be $3.69 \mathrm{MPa}$ and $1.73 \mathrm{MPa}$ in phase 2 and phase3 respectively. The corresponding slip $\left(\mathrm{s}_{0}\right)$ at the maximum bond shear stress was found to be $0.05 \mathrm{~mm}$ and 0.022 $\mathrm{mm}$ in phase 2 and 3 respectively. Since the CFRP sheet covers the entire surface of the wall panel, the ratio $\frac{b_{f}}{b_{c}}$ is equal to 1 . 


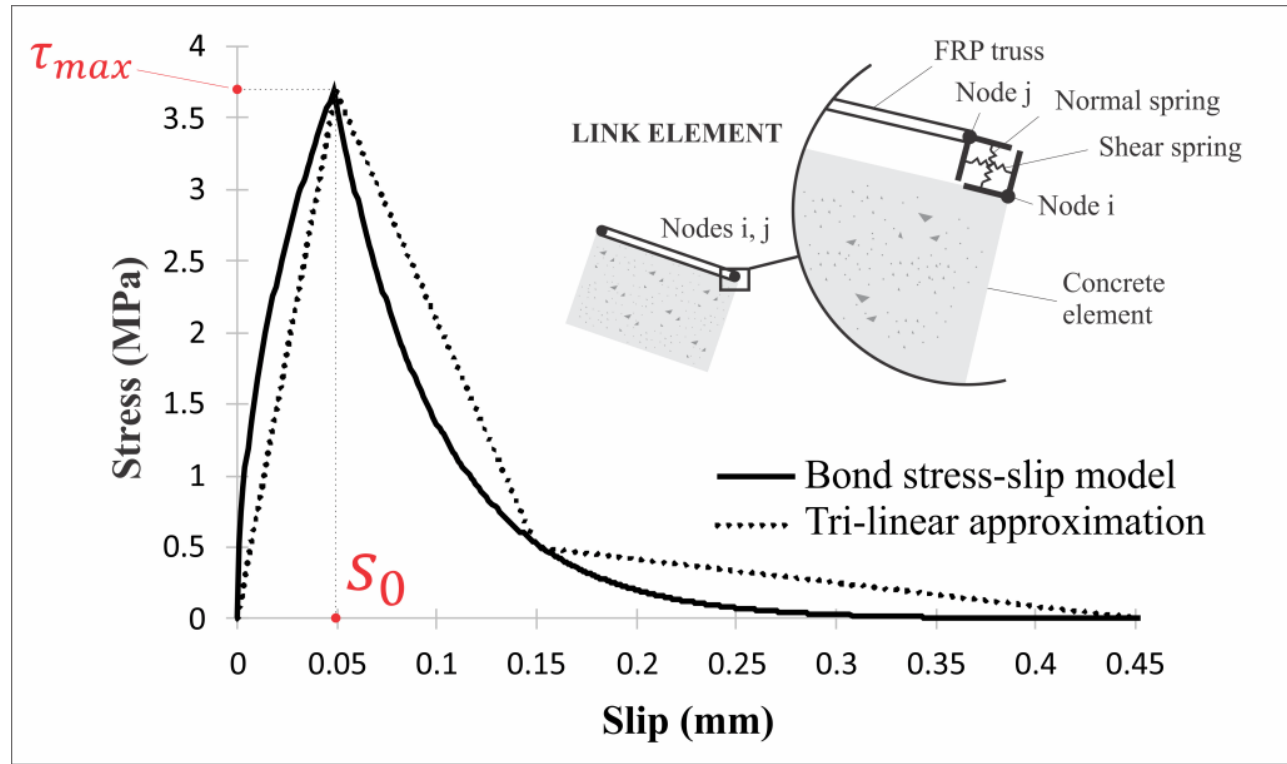

Fig. 9. Schematic of interface element and tri-linear bond stress-slip relationship

\subsubsection{Confining Effect of CFRP Layers}

The numerical models in this study are two-dimensional and there is a need to consider the OOP effect of the externally bonded CFRP sheets; hence, an independent analytical parametric study was conducted using the Abaqus program to investigate the OOP confining effect of CFRP layers on the concrete. Three-dimensional numerical shear wall models having different aspect ratios, number of CFRP layers and thicknesses in the horizontal and vertical directions were subjected to axial compression loading. By calculating the difference between the average OOP stresses in the concrete elements of models with and without the CFRP layers, the study found that there is a considerable concrete confinement effect in the CFRP-strengthened shear walls. From the parametric study, it can be concluded that as the thickness or the aspect ratio of the wall increases, the OOP compressive stresses in concrete and as a result the confinement effects due to CFRP decreases. The analysis results also showed that the confinement effects vary in different regions of the wall and it is greatest at the lower corners of the wall. 
To consider the confinement effect in the two-dimensional model, an equivalent amount of OOP steel reinforcement ratio was computed based on the following equation and added to the concrete elements (the steps to derive equation (9) can be found in Appendix B).

$$
\rho_{o}=\frac{f_{c}}{F_{y}}
$$

where, $\rho_{o}$ is the equivalent OOP steel reinforcement ratio, $f_{c}$ is the OOP compressive stress in concrete elements due to the presence of the CFRP layers, and $F_{y}$ is the yield stress of the OOP steel material. The OOP reinforcement ratio is utilized to compute the strength and ductility enhancements in the concrete due to the confinement according to Wong et al. (2013). Based on the parametric study, it was found that, on average, the OOP compressive stress developed in concrete due to CFRP is $3.5 \mathrm{MPa}$ which results in an equivalent OOP reinforcement ratio of about $0.9 \%$ (assuming $F_{y}=400 \mathrm{MPa}$ ). This OOP reinforcement ratio was added to the concrete elements located at the bottom one-third of the wall for all $2 \mathrm{D}$ models. The $0.9 \%$ ratio is only appropriate to walls with design parameters within the range investigated in the parametric study. Future work is needed to develop relationships to predict OOP compressive stress in concrete of other wall geometry and CFRP strengthening scheme.

\subsection{Modelling of the Anchor System}

As explained earlier, the anchor system is a critical component in the design of a CFRP strengthening system; therefore, special attention should be given to include the influence of this component in the numerical model. There are two sources of flexibility at the junction of the wall and foundation that need to be considered: 1) flexibility due to the pulley mechanism, which is a function of the development length of the CFRP in the OOP direction; and 2) flexibility of the tube anchor, which depends on the stiffness of the tube, as shown in Fig.10. 


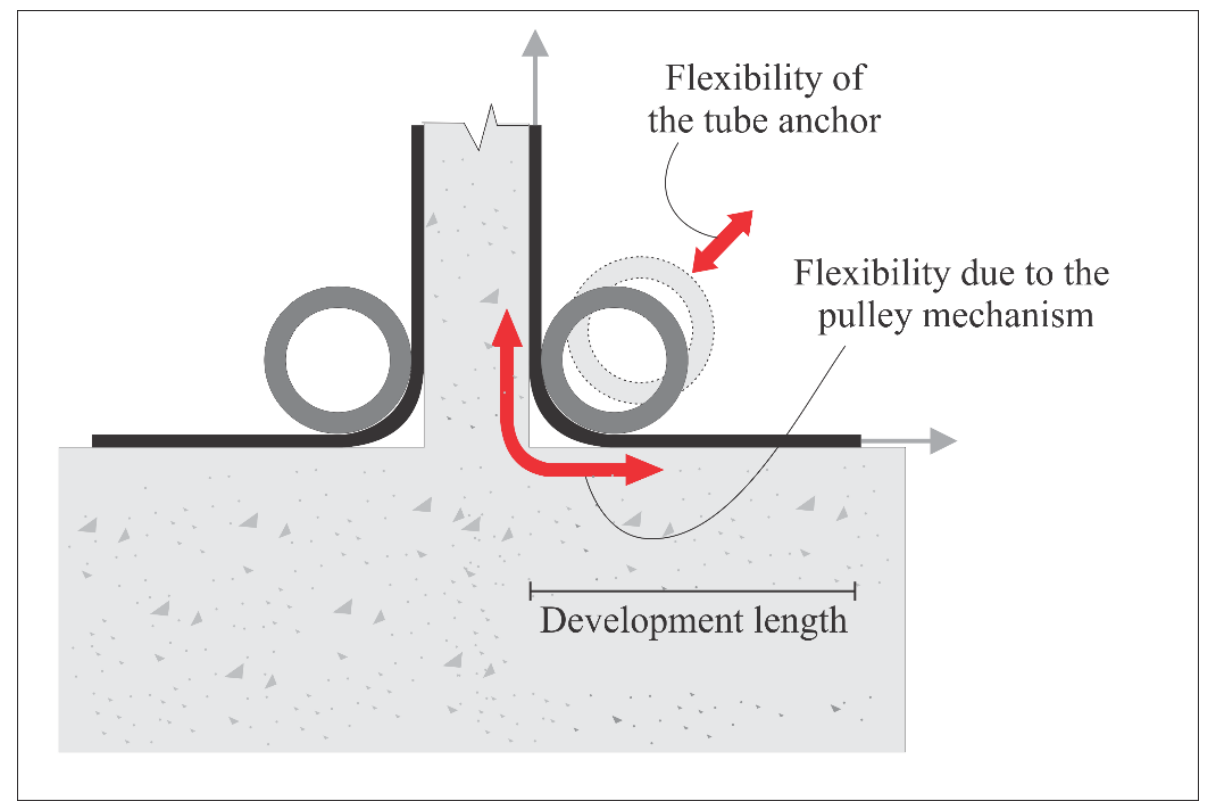

Fig. 10. Sources of influences of anchor system: pulley mechanism and tube anchor flexibility

Two different approaches were followed to model the effects of the development length; in the first approach, perfect bond was assumed between the CFRP trusses and concrete elements at the anchor bolt locations of the tube anchor (i.e. a common node was used to connect the two elements); whereas over the interval between adjacent anchor bolts, link elements having different bond-slip relationships representing the flexibility of the anchor system were used to connect the CFRP trusses to concrete elements, as shown in Fig. 11 (a). In the second approach, all nodes of the CFRP trusses and concrete elements at the junction of the wall and foundation block were directly connected to each other using common nodes (i.e. prefect bond assumption); however, truss elements were used to model groups of uniaxial elastic springs with different stiffnesses over the interval regions between the anchor bolts to simulate the influence of the OOP CFRP on the foundation block. These springs have higher stiffnesses near the bolts (red springs) and lower stiffnesses at the middle (yellow springs), as shown in Fig. 11 (b). 


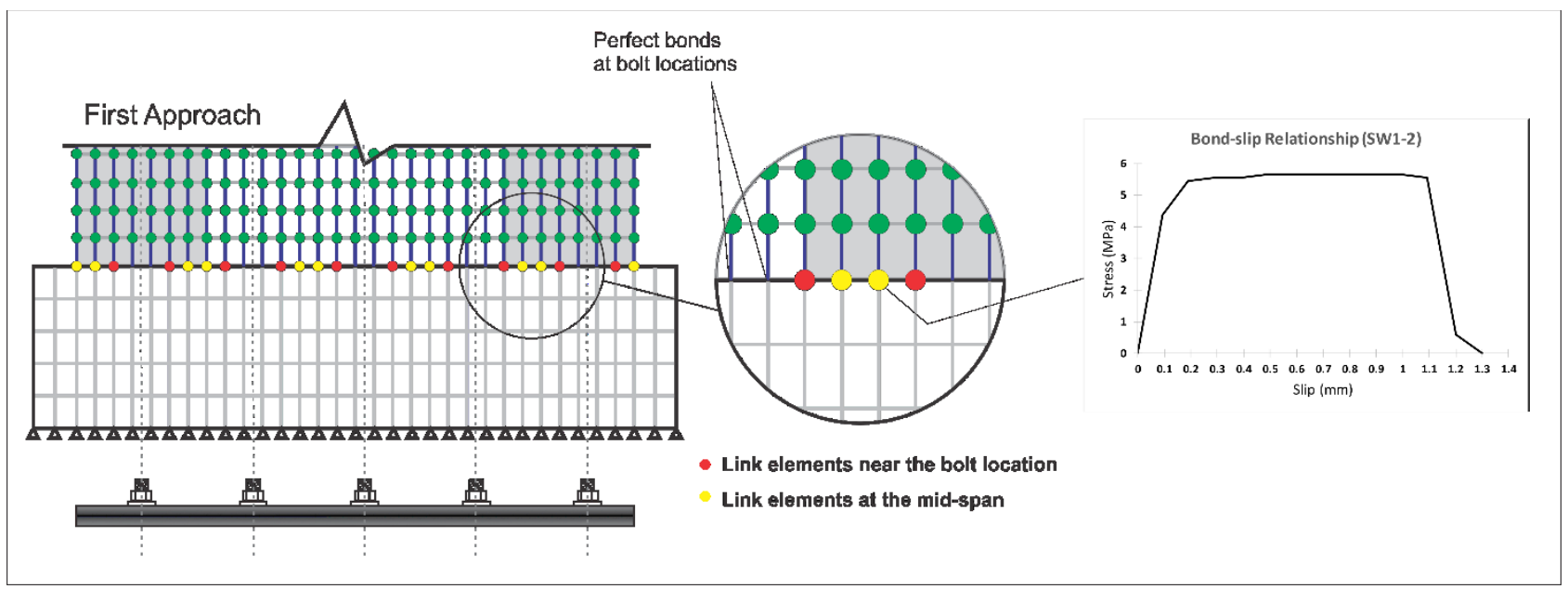

(a)

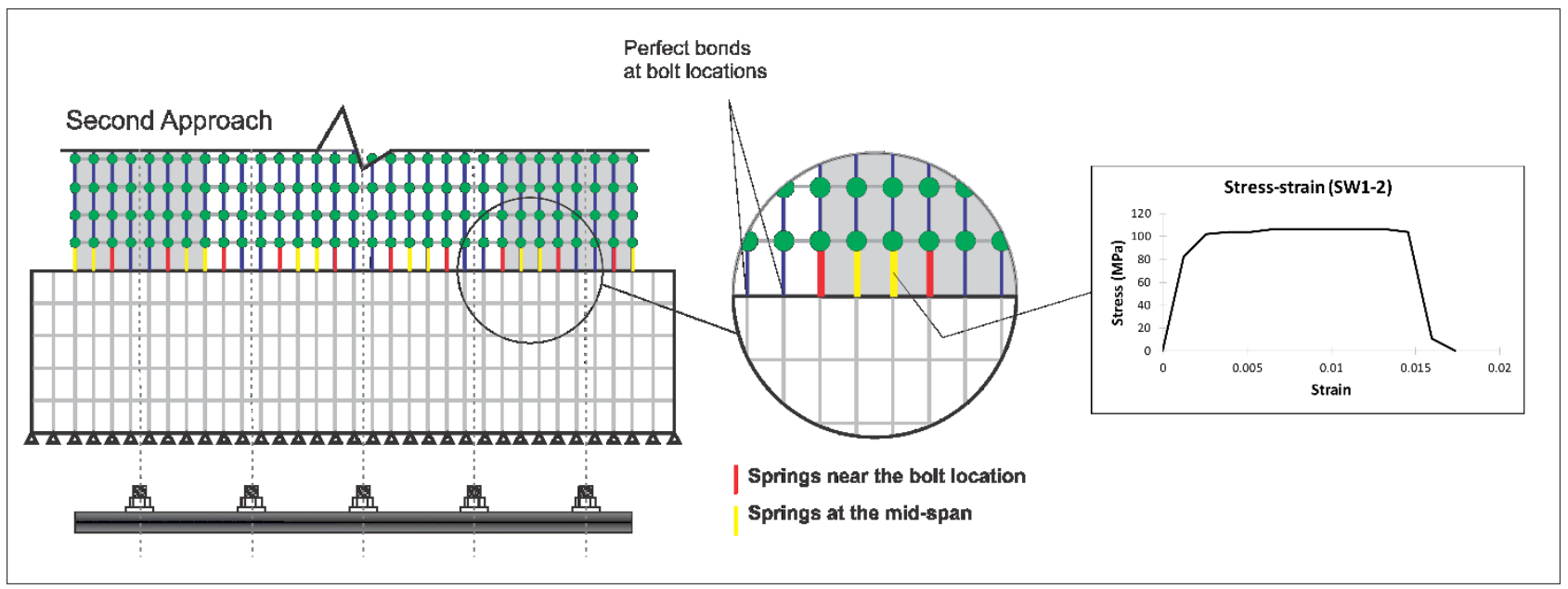

(b)

Fig. 11. (a) First approach using link elements; (b) Second approach using springs

In both modelling approaches, the parts of the anchor tube between the bolts were assumed to act as a pulley that transfers the load from the in-plane vertical CFRP connected to the wall to the OOP CFRP attached to the top of the foundation block. Based on the concept of pulley, the force developed in the OOP CFRP sheets should be equal to the force in the vertical CFRP sheets at the junction of the wall and foundation block. To determine the bond-slip and stress-strain relationships of the link elements and springs for the first and second modelling approaches, a small section of the OOP CFRP was separately modeled in VecTor2, as shown in Fig. 12. The 
length of the OOP CFRP sheets, which is the development length of the in-plane vertical CFRP sheets is $350 \mathrm{~mm}$ as reported by Hiotakis (2004) in the experiment. The section's width is equal

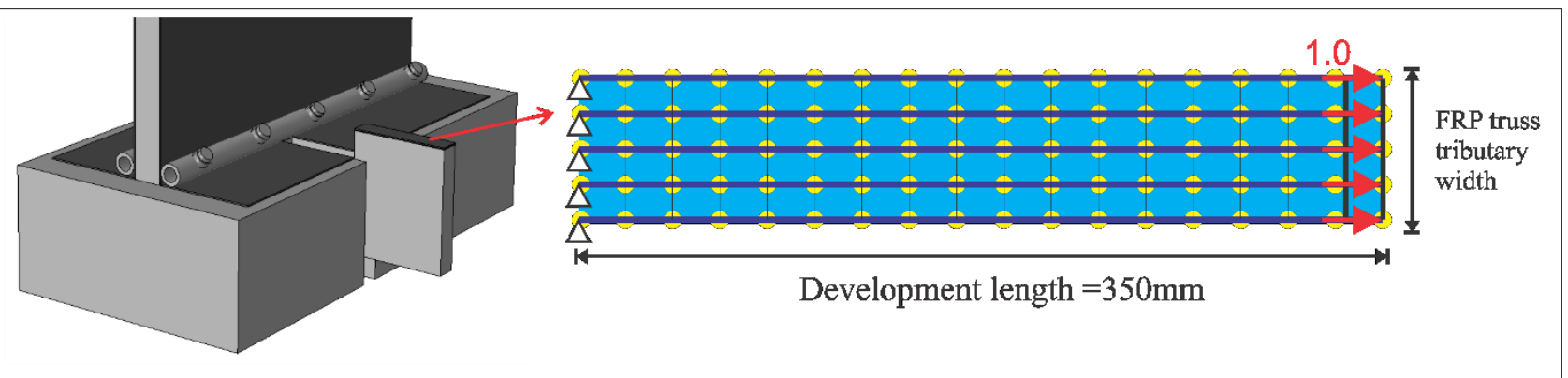

Fig. 12. Modelling a small section of the development length

to the tributary width of truss element modelling the CFRP. In order to obtain a more accurate response, a finer mesh was used in the section's model. The concrete was fixed at one end, and the truss elements at the free end were subjected to displacement load. The force-displacement relationship resulted from the FE model representing the OOP CFRP sheets was transformed to an equivalent bond-slip relationship and assigned to link elements defined at the junction of the wall and foundation block (approach 1), or was converted to an equivalent stress-strain relationship and assigned to truss elements simulating the flexibility of the anchor system (approach 2).

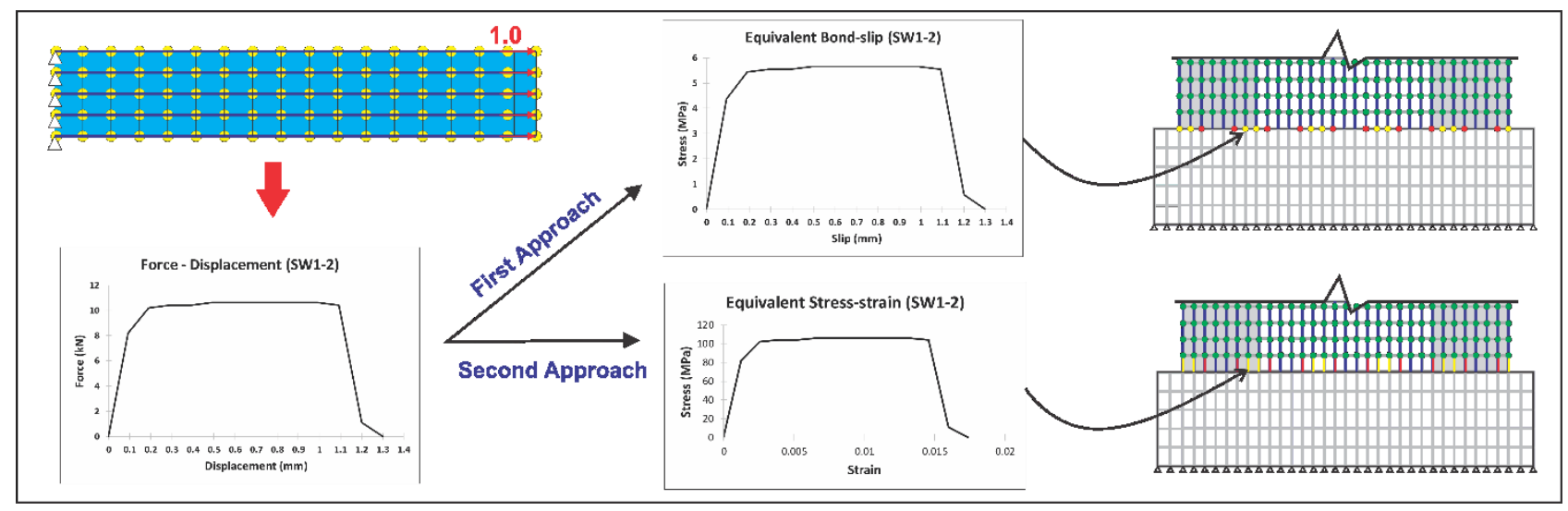

Fig. 13. Force-displacement conversion to bond-slip and stress-strain relationships 
Fig. 13 shows how the local OOP CFRP model is used to account for the effect of the anchor system in the global shear wall model. To obtain the bond-slip relationship from the forcedisplacement relationship for the first modelling approach, the force is divided by the link element's tributary area, which yields the bond stress, and the slippage is equal to the displacement. Fig. 14 shows a schematic of areas tributary to link elements.

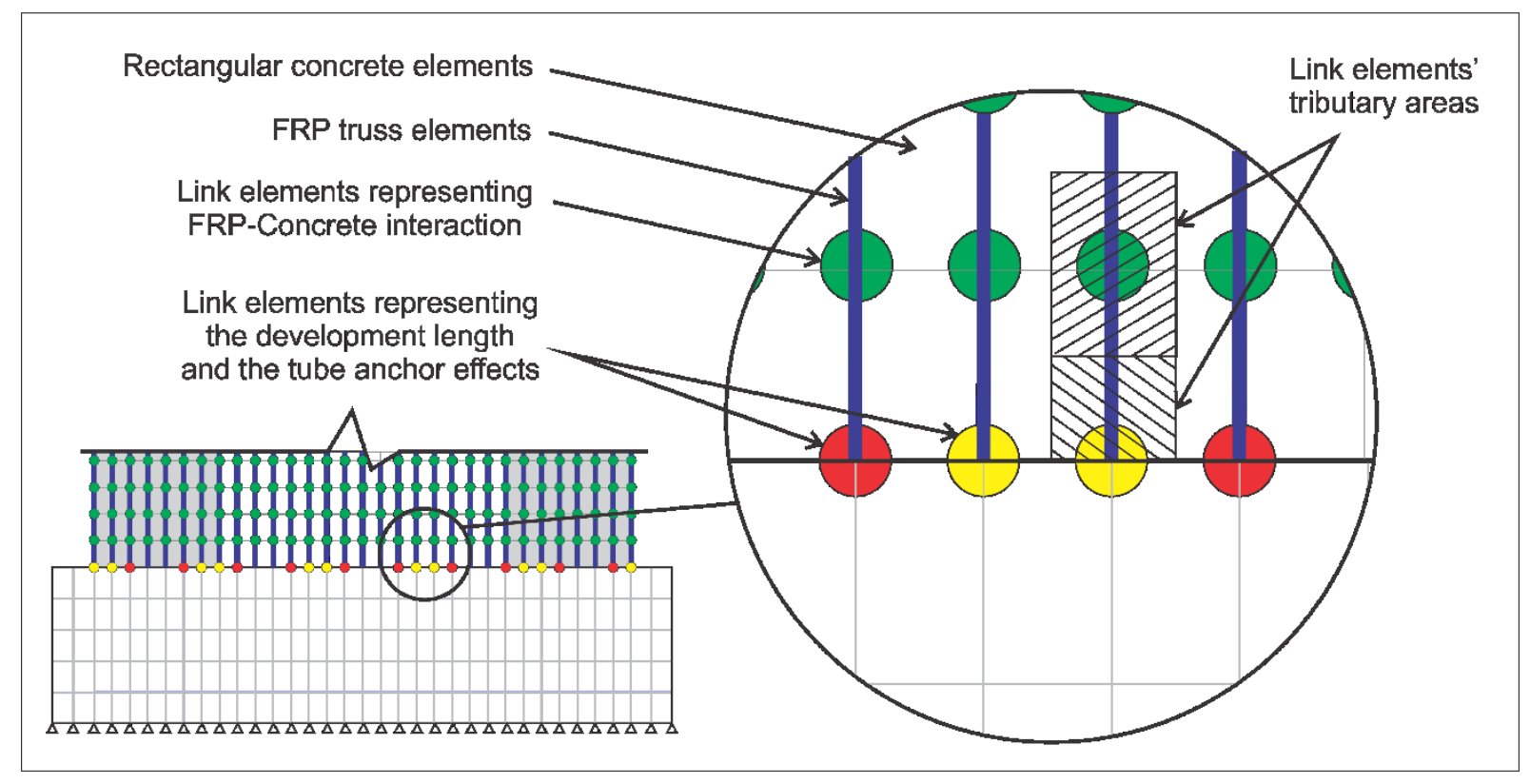

Fig. 14. Areas tributary to link elements

Transforming the force-displacement relationship to stress-strain relationship for the second modelling approach includes dividing the force by the spring's cross-section area, which gives the stress, and dividing the displacement by the spring's length which yields the strain.

As mentioned earlier, in addition to the pulley mechanism, the flexibility of the tube anchor can also influence the force distribution in the CFRP sheets at the base of the wall. To account for this effect, the peak force resulted from the local OOP CFRP model was applied as point loads at the locations of CFRP trusses along one span of the tube anchor, as shown in Fig. 15(a) 
(Approximated as a simply supported beam), and the consequent deflection was added to the forcedisplacement relationship as additional deformation (see Fig. 15(b). The small deflection in the

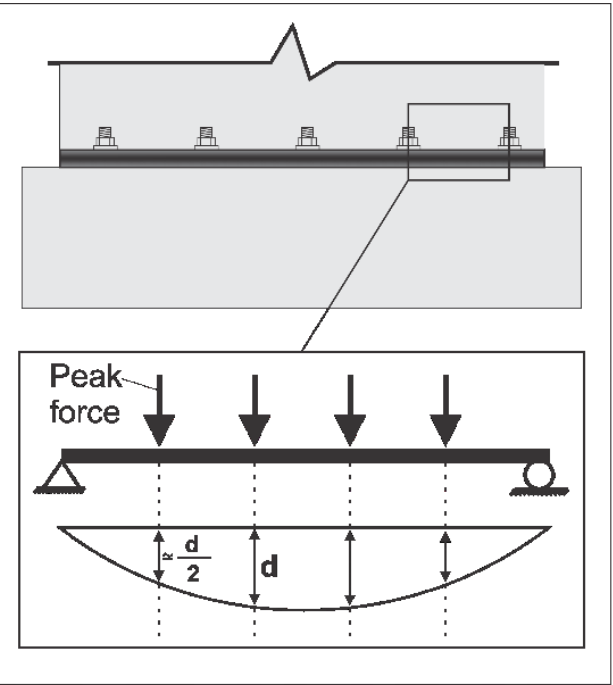

(a)

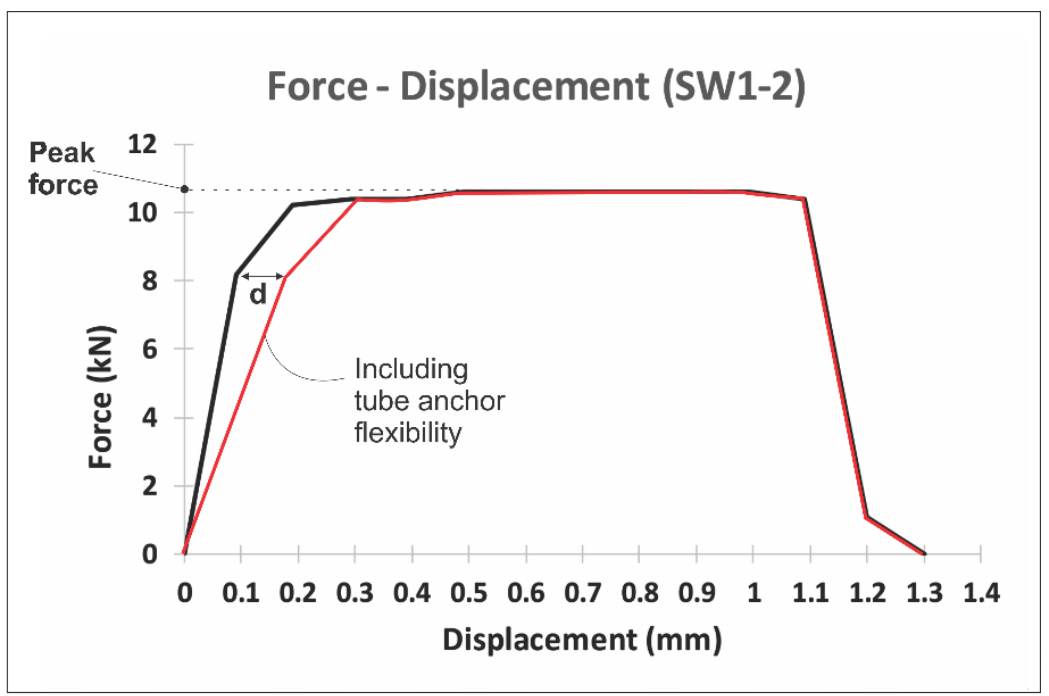

(b)

Fig. 15. Finding deflection in one span of the tube anchor

tube anchor provides additional flexibility and decreases the stiffness in the bond-slip and stressstrain relationships.

For the purpose of comparison, two additional cases, in which the influence of the anchor system was ignored, were also investigated: first, using common nodes between the CFRP trusses and concrete elements, assuming prefect bond for all nodes at the junction of the wall and foundation block and, hereafter, will be referred to as case (a). The perfect bond assumption in case (a), which ignores the detrimental effect of FRP debonding on the overall behaviour, is typically made by engineers and researchers in modelling the effect of anchor system on CFRP strengthened/repaired RC structural elements. The second case (b) further investigates the influence of the base anchor of the FRP on the overall performance of the wall by neglecting the anchorage contribution of the tube anchor system while considering the bond interaction between 
the FRP and concrete by link elements between the CFRP trusses and concrete substrate elements. A schematic of the two cases is shown in Fig. 16.

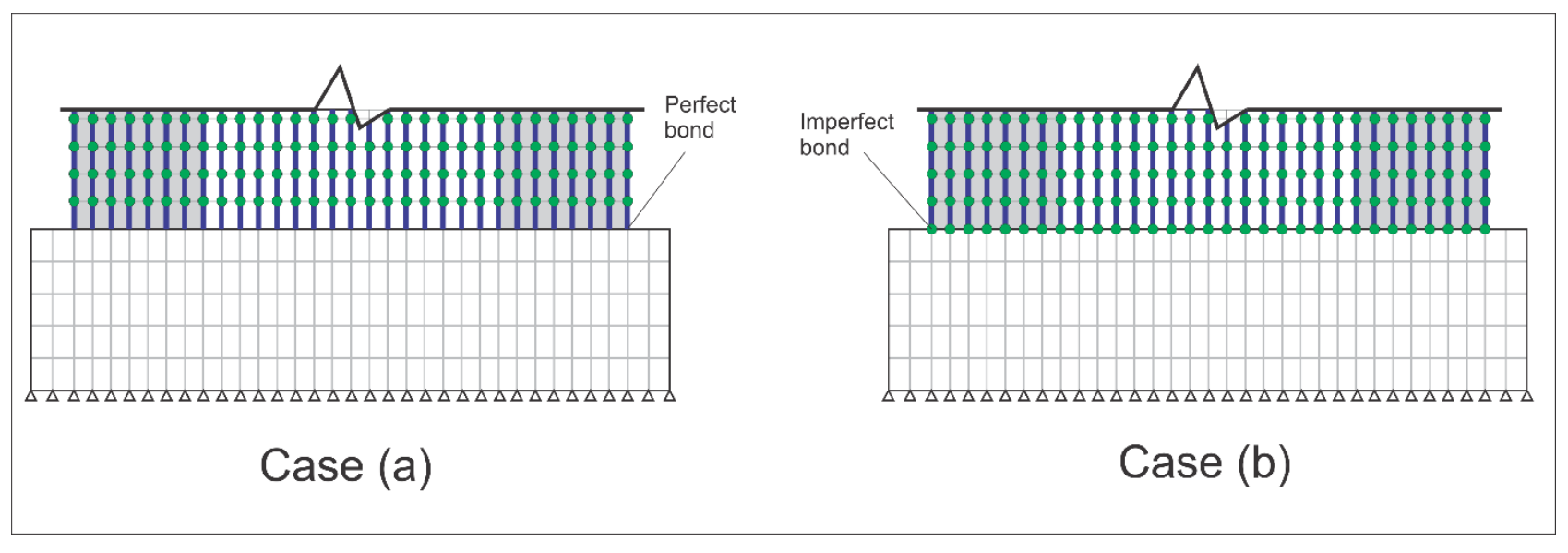

Fig. 16. Schematic of perfect and imperfect bonds in Case (a) and Case (b)

\subsection{Loading}

The shear walls were exposed to a reversed displacement controlled cyclic lateral load up to failure. No axial load was applied on the specimens. The lateral load was modeled by controlling the displacement of a node located at the center of the cap beam according to the loading pattern in the experiment. The self-weight of the wall was considered using gravity loads calculated based on the density of concrete elements. 


\section{RESULTS AND DISCUSSION}

Before discussing the analysis results, it is worth mentioning that in all the analyses preformed in this paper, the same set of material models and analysis parameters, as those described in the previous section, were used to eliminate problems associated with material characterisation and to have an unbiased assessment of the accuracy and the range of applicability of the proposed modelling procedure.

\subsection{Significance of Considering the Anchor System}

In Fig. 17, the computed responses of approach (1), case (a) and case (b) are plotted against the measured response of the strengthened shear wall SW1-2 (Phase 2). This plot emphasizes the significance of considering the influence of the pulley mechanism and the flexibility of the tube anchor. In both case (a) and case (b), in which the influence of the anchor system was not considered, the peak loads are significantly different from the measured result. It is obvious from Fig. 17 case (a) that the perfect bond assumption results in an unrealistic highest peak load

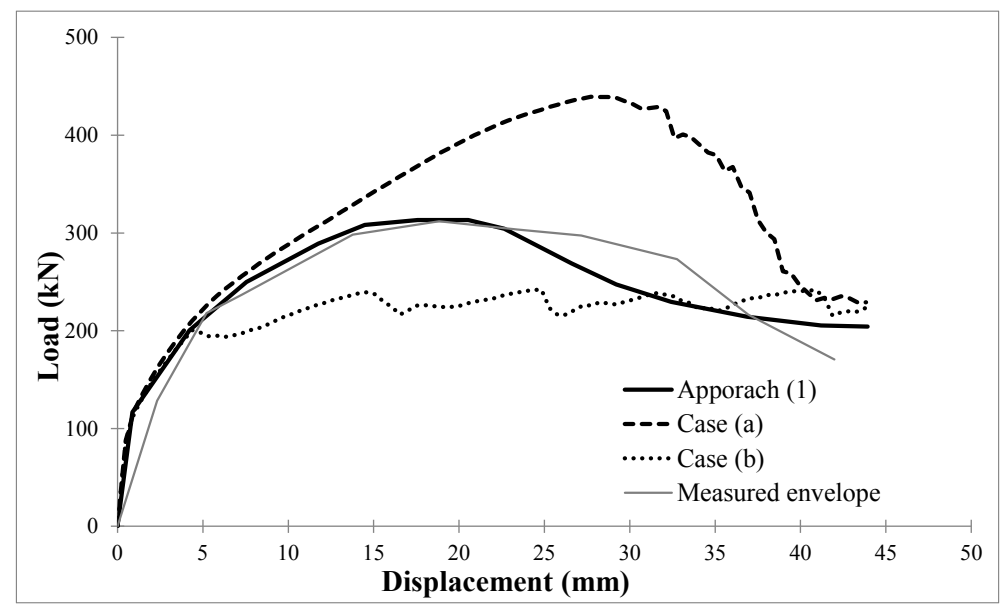

Fig. 17. Computed responses of approach (1), Case (a) and Case (b) compared with the measured envelope (SW1-2) 
capacity and serves as upper bound load capacity. In comparison, as observed in the experiments, considering the influence of the anchor system, with the deformations of the tube anchor and the OOP CFRP sheet, the stress drops significantly in the vertical CFRP sheet between the bolts. This leads to a lower peak load capacity of the wall and consequently, due to stress redistribution, an increase in the stress of the vertical FRP at the fixed location of the anchor bolts. The model of the first approach, as shown in Figs. 17 and 18, accurately captures this behaviour of the strengthened wall, considering the influence of the anchor system. In comparison, the model case (b) which considers the debonding interaction behaviour between FRP and concrete, but ignores entirely the anchorage contributions of the anchor system, results in the lowest peak load capacity of the wall.

(a)

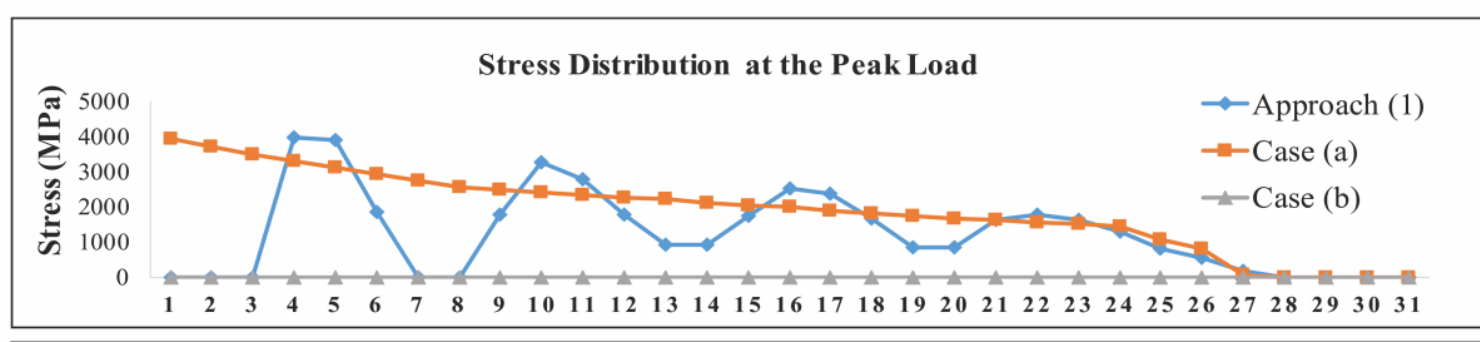

(b)
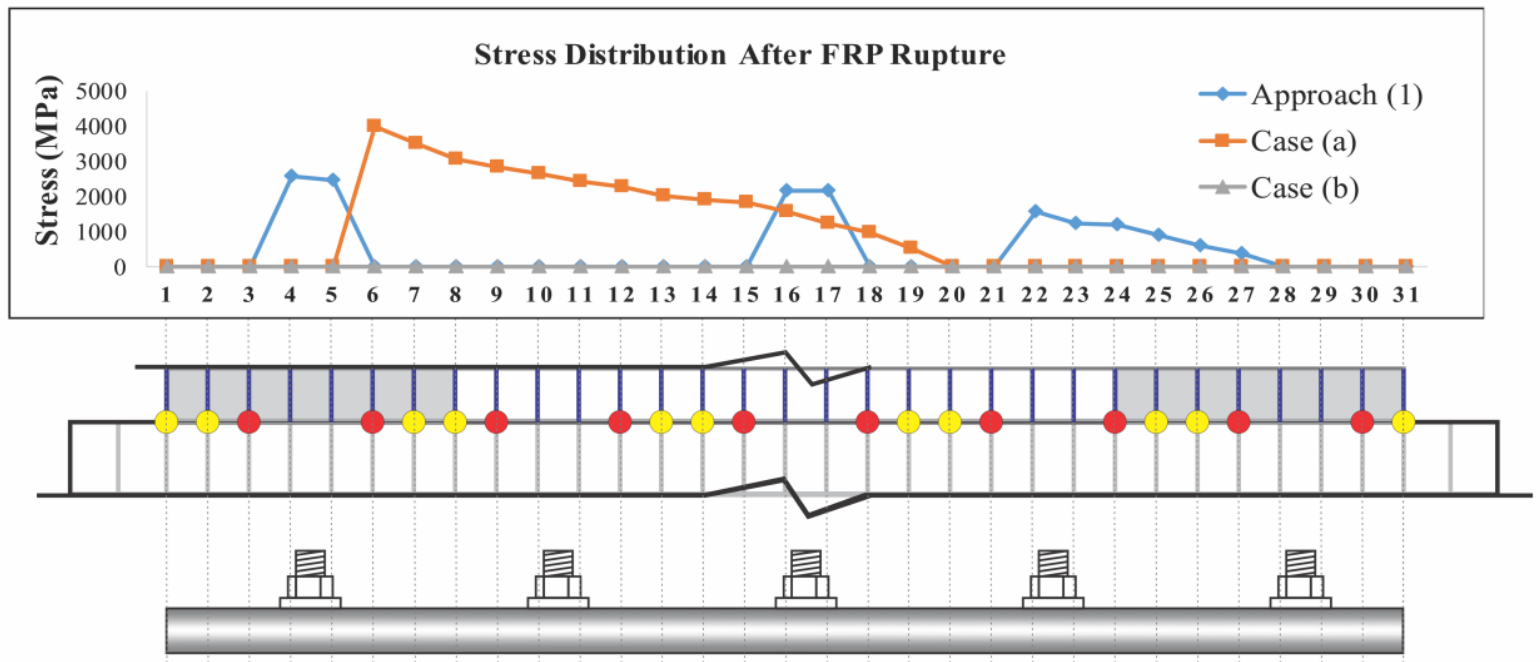

Fig. 18. Stress distribution in the CFRP trusses at the Base of the Wall (SW1-2), (a) at the peak load, (b) after CFRP rupture 
As shown in Fig. 18(a) of the stress profile of the vertical CFRP materials at peak load, all the CFRP at the wall base in case (b) are debonded and carry no stress, resulting in underestimation of the peak load. Case (b) serves as the lower bound capacity of the wall.

The analytical results of ten control and CFRP-strengthened shear walls tested in Phase 2 and 3 are presented and compared to the experimental results in the following sections.

\subsection{Phase 2 Shear Walls}

The hysteretic responses of the numerical models are plotted against the measured responses in Figs. 19 and 20. In general, the computed results agreed quite well with the measured responses considering the complexity of the problem. The numerical models were able to accurately capture the strength degradation and the pinching effect. The initial stiffness and the pre-peak behaviour were well predicted. The ductility and energy dissipation capacity of the strengthened walls were slightly underestimated with the analysis stopped slightly before the termination of the tests due to rupture of the vertical steel reinforcement in the numerical models, leading to termination of the analyses.

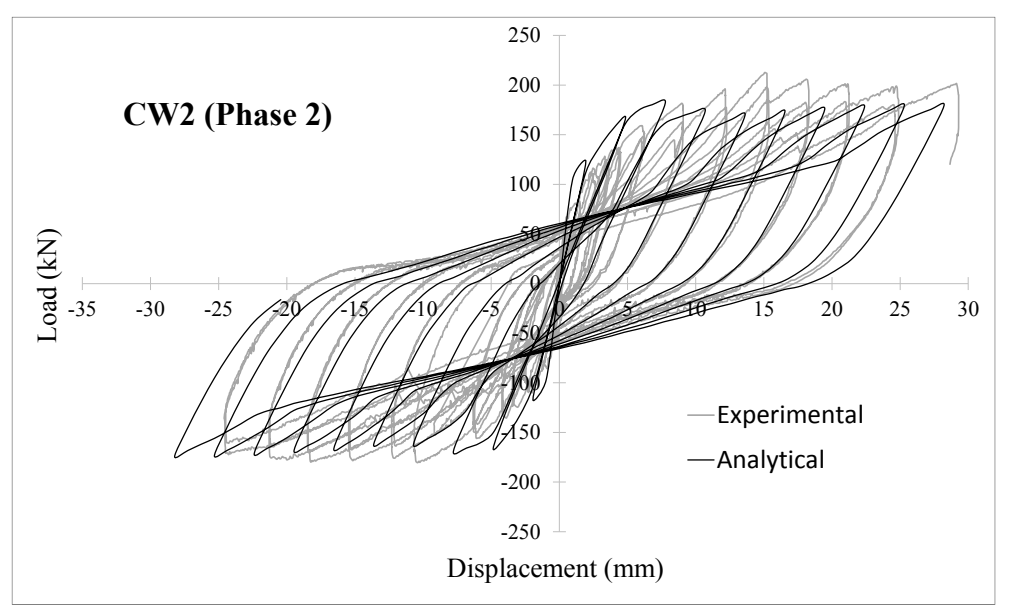

Fig. 19. Observed and calculated responses of the control wall CW2 - phase 2

Fig. 20 compares the computed results using the first and second approaches. As can be seen, the responses of both approaches are similar in terms of peak load and ductility of the shear walls. 

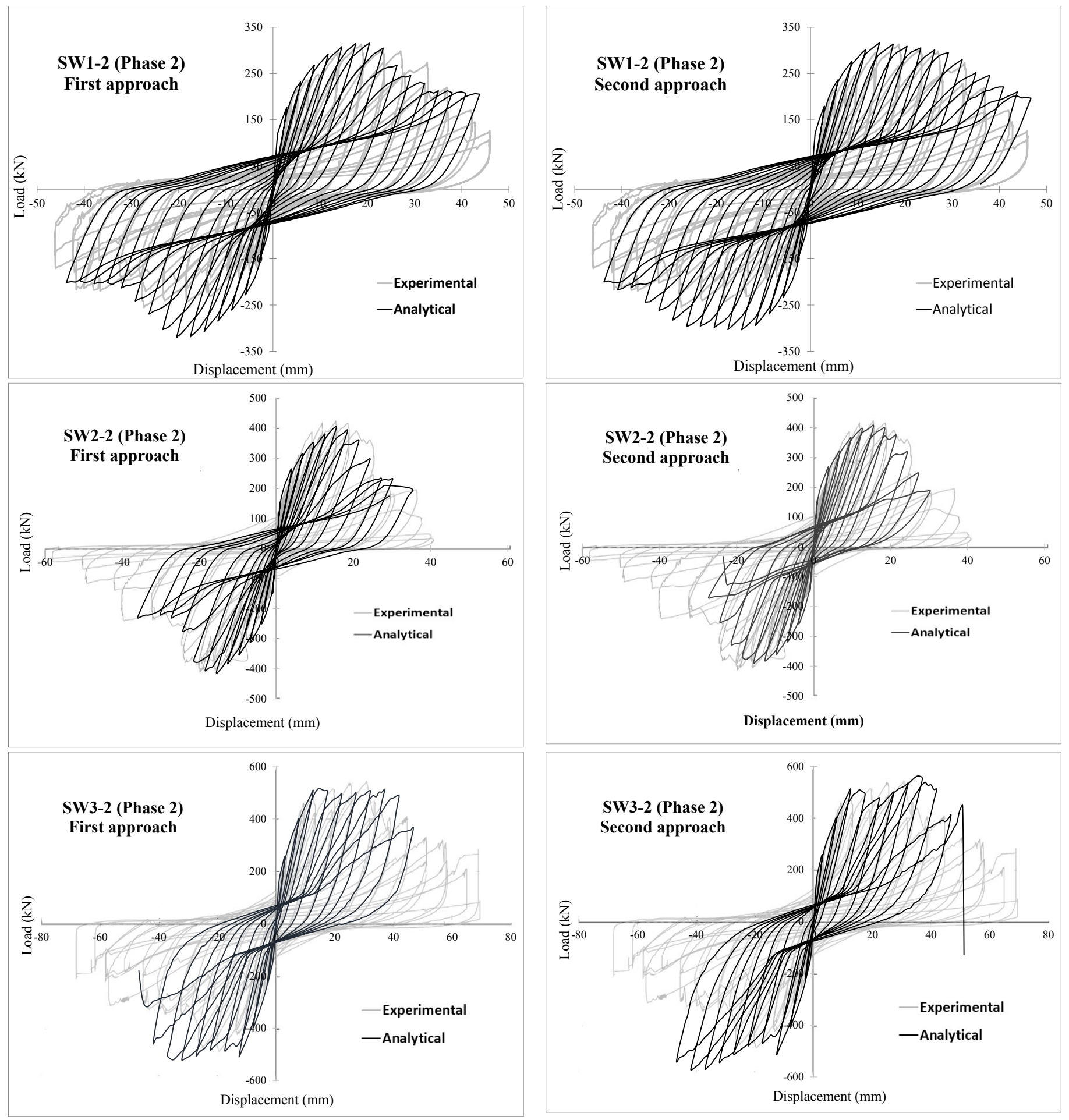

Fig. 20. Observed and calculated responses of the strengthened shear walls in phase 2 using first and second approaches 
Comparison between the computed and measured peak loads shown in Table 3, also leads to the conclusion that the responses of both approaches are almost the same, in terms of peak loads.

TABLE 3. Computed against measured peak loads (Phase 2)

\begin{tabular}{|c|c|c|c|c|c|c|c|c|}
\hline \multirow[b]{2}{*}{ Approach } & \multirow[b]{2}{*}{ Specimen } & \multicolumn{3}{|c|}{$\begin{array}{l}\text { Observed peak load } \\
\qquad(\mathrm{kN})\end{array}$} & \multicolumn{3}{|c|}{$\begin{array}{l}\text { Calculated peak load } \\
\qquad(\mathrm{kN})\end{array}$} & \multirow[b]{2}{*}{ Cal./Obs. } \\
\hline & & Positive & Negative & Avg & Positive & Negative & Avg & \\
\hline- & CW2 & 213 & -180 & 197 & 183 & -174 & 179 & 0.91 \\
\hline \multirow[t]{3}{*}{ First } & SW1-2 & 313 & -275 & 294 & 315 & -319 & 317 & 1.07 \\
\hline & SW2-2 & 426 & -412 & 419 & 403 & -413 & 408 & 0.97 \\
\hline & SW3-2 & 541 & -487 & 514 & 517 & -521 & 519 & 1.01 \\
\hline \multirow[t]{3}{*}{ Second } & SW1-2 & 313 & -275 & 294 & 316 & -303 & 310 & 1.05 \\
\hline & SW2-2 & 426 & -412 & 419 & 407 & -388 & 398 & 0.95 \\
\hline & SW3-2 & 541 & -487 & 514 & 563 & -571 & 567 & 1.10 \\
\hline
\end{tabular}

As shown in Table 4, the numerical models using either first or second approach can accurately predict the failure sequence of Phase 2 shear walls. The failure sequence, in all cases, begins with yielding of the extreme flexural steel reinforcement; then, the CFRP sheet debonds near the bottom edges of the wall; followed by crushing of the concrete at the toes of the wall, and finally the CFRP reaches its rupture strength capacity in tension.

TABLE 4. Computed against measured sequence of failure (Phase 2)

\begin{tabular}{|c|c|c|c|c|c|c|c|c|c|}
\hline \multirow[b]{2}{*}{ Appr. $^{\mathrm{b}}$} & \multirow[b]{2}{*}{ Spec. $^{c}$} & \multicolumn{4}{|c|}{$\begin{array}{c}\text { Failure Sequence }(\text { Observed })^{\mathrm{a}} \\
\text { Disp. }(\mathrm{mm}), \text { Force }(\mathrm{kN})\end{array}$} & \multicolumn{4}{|c|}{$\begin{array}{c}\text { Failure Sequence }(\text { Calculated })^{\mathrm{a}} \\
\text { Disp. }(\mathrm{mm}), \text { Force }(\mathrm{kN})\end{array}$} \\
\hline & & Yield & Debond & $\mathrm{CC}$ & $\overline{C R}$ & Yield & Debond & $\mathrm{CC}$ & $\mathrm{CR}$ \\
\hline- & CW2 & 4,121 & $\mathrm{~N} / \mathrm{A}$ & 15,184 & $\mathrm{~N} / \mathrm{A}$ & 4,164 & $\mathrm{~N} / \mathrm{A}$ & 19,195 & N/A \\
\hline \multirow[t]{3}{*}{ First } & SW1-2 & 2,150 & 5,217 & 14,223 & 19,313 & 3,177 & 12,297 & 16,315 & 38,328 \\
\hline & SW2-2 & 3,227 & 9,360 & 12,415 & 15,426 & 3,232 & 13,377 & 16,413 & 36,230 \\
\hline & SW3-2 & 3,247 & 13,414 & 20,426 & 26,413 & 3,226 & 9,418 & 17,534 & 43,318 \\
\hline \multirow[t]{3}{*}{ Second } & SW1-2 & 2,150 & 5,217 & 14,223 & 19,313 & 3,169 & 8,272 & 17,307 & 30,294 \\
\hline & SW2-2 & 3,227 & 9,360 & 12,415 & 15,426 & 3,237 & 12,404 & 15,329 & 19,367 \\
\hline & SW3-2 & 3,247 & 13,414 & 20,426 & 26,413 & 4,289 & 11,469 & 20,457 & 38,295 \\
\hline
\end{tabular}

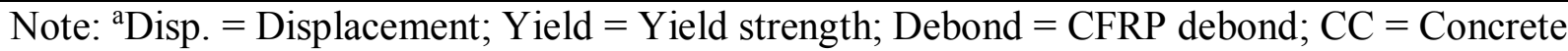
crush; CR = CFRP rupture.

${ }^{\mathrm{b}}$ Appr. $=$ Approach.

'Spec. $=$ Specimen . 
In all cases, the numerical analyses were terminated due to the vertical steel reinforcement reaching its ultimate strength. Fig. 21 compares the measured failure sequence against the calculated failure sequence in shear wall SW1-2 (Phase 2). The onset of yielding of the flexural reinforcement is well predicted. The onset of FRP debonding as well as FRP rupturing are overestimated.

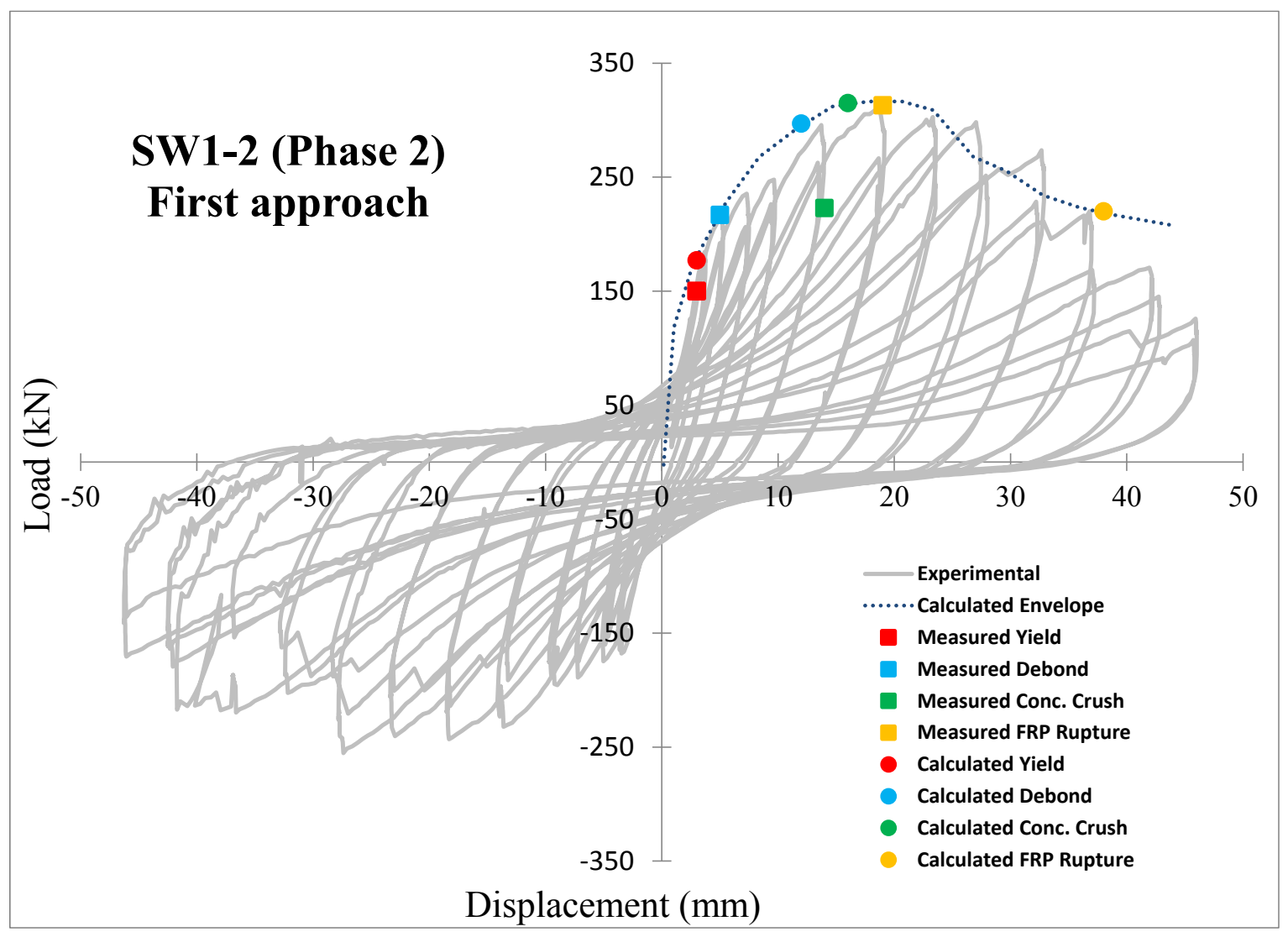

Fig. 21. Observed and calculated sequence of failure in wall SW1-2 (phase 2)

Fig 22, 23 and 24 shows the stress distribution in the vertical reinforcement, concrete elements and FRP trusses respectively in the wall SW1-2 (Phase 2). 


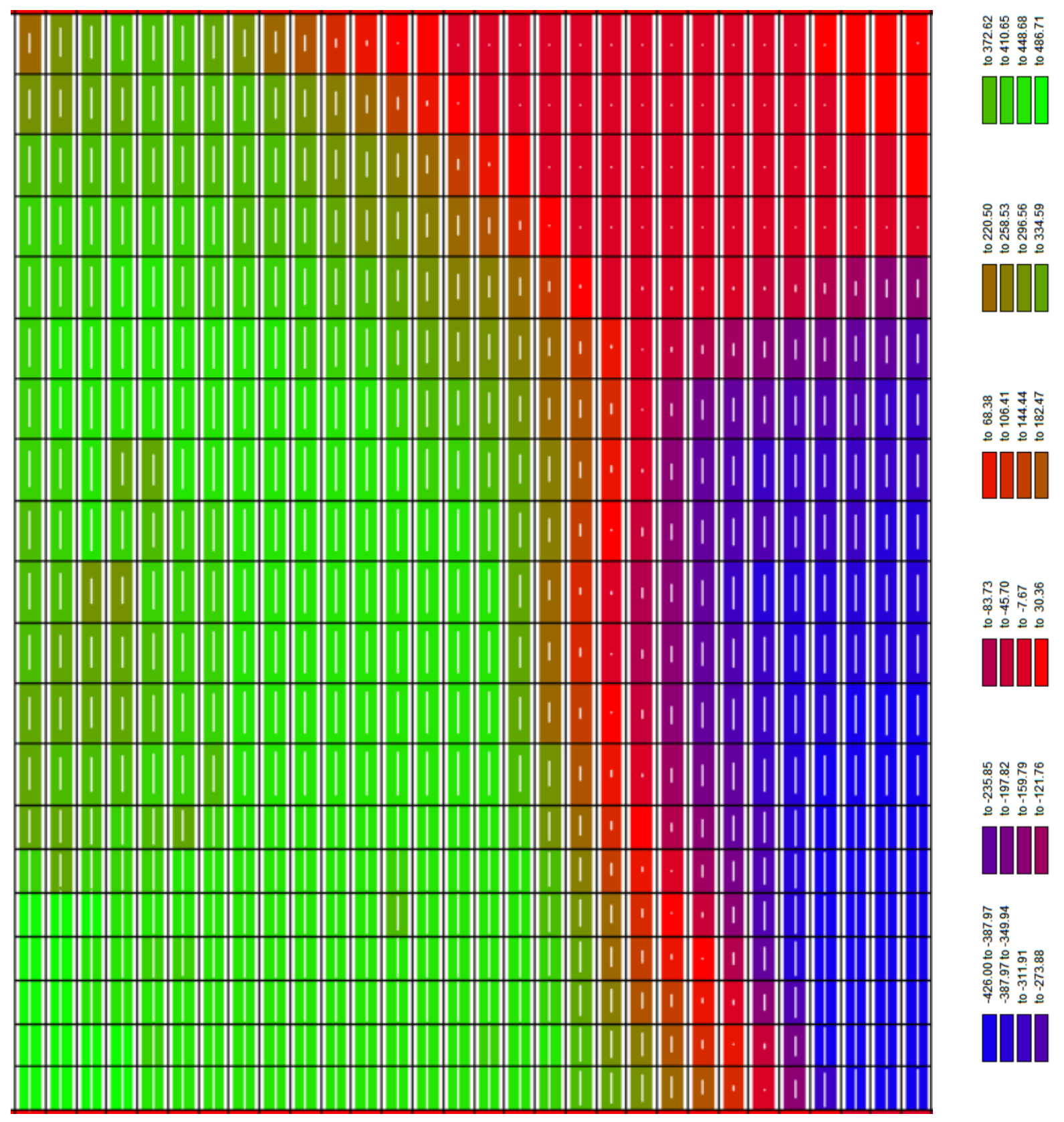

Fig. 22. The stress distribution in the vertical reinforcement in wall SW1-2 (Phase 2) at the peak load 


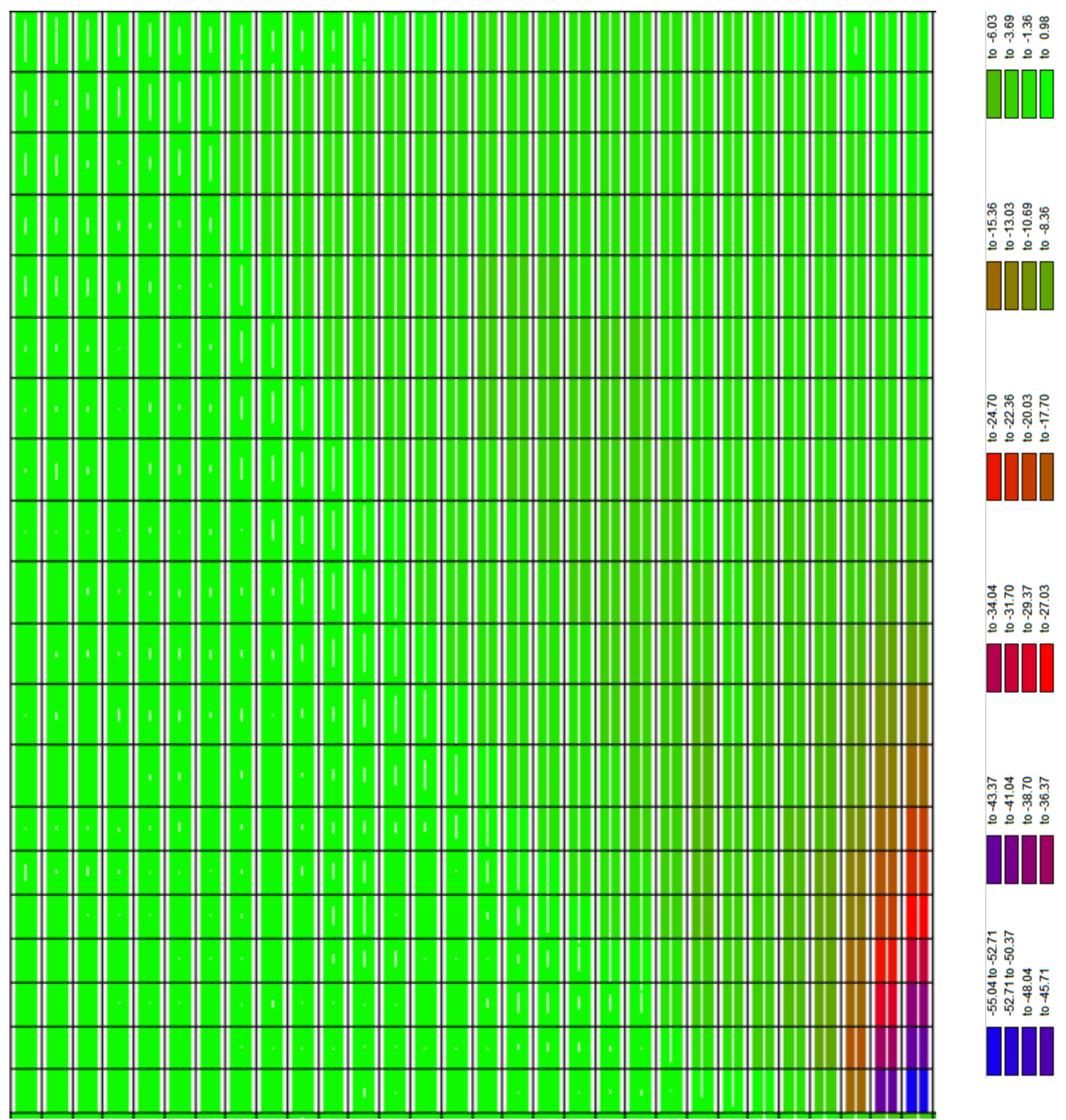

Fig. 23. The stress distribution in the concrete in wall SW1-2 (Phase 2) at the peak load 


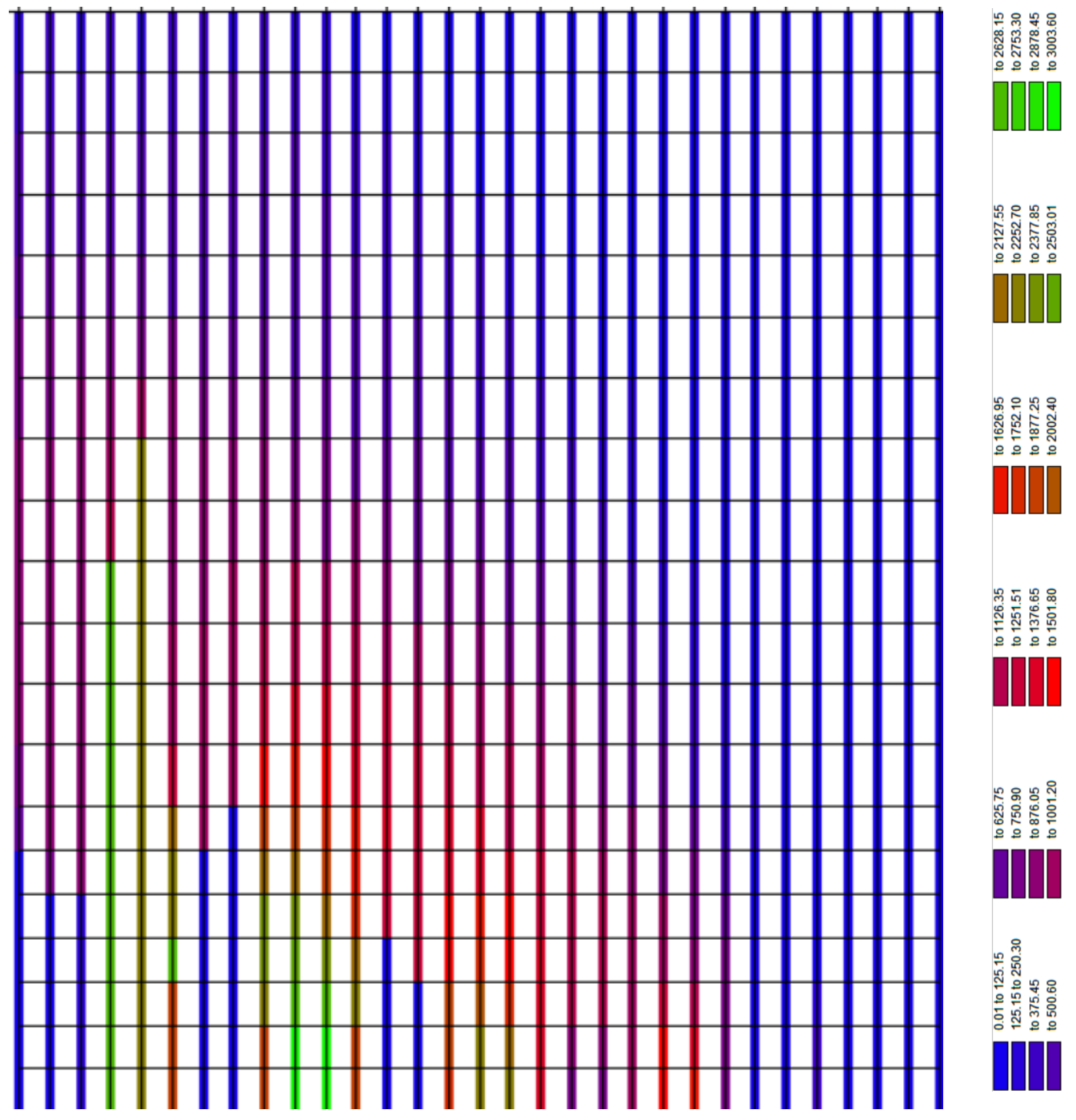

Fig. 24. The stress distribution in the FRP truss in wall SW1-2 (Phase 2) at the peak load 


\subsection{Phase 3 Shear Walls}

Fig. 25 shows the computed hysteretic responses versus the experimental results of shear walls from Phase 3 of the test program. The pinching effect in all control walls is overestimated. In most computed responses, the peak load is better predicted in the push direction and underestimated in the pull direction. The reason for the asymmetric behaviour in the push and pull directions of the test results could be due to the slight shifting of the reinforcing steel rebar assemblies during the construction process of the shear wall test specimens (Woods et al. 2016). Table 5 compares the computed results against the measured peak loads in Phase 3.The comparison shows good correlation between the observed and calculated peak loads. The asymmetric response in SW3Phase 3 shear wall is attributed to the load protocol for this particular test. Symmetric reversed cyclic load was initially applied, which was then followed by cyclic load in the positive direction up until the test was stopped. VecTor2 replicated this loading protocol during the numerical analysis.

TABLE 5. Computed against measured peak loads (Phase 3)

\begin{tabular}{|c|c|c|c|c|c|c|c|}
\hline \multirow[b]{2}{*}{ Specimen } & \multicolumn{3}{|c|}{$\begin{array}{l}\text { Observed Peak Load } \\
\qquad(\mathrm{kN})\end{array}$} & \multicolumn{3}{|c|}{$\begin{array}{l}\text { Calculated Peak Load } \\
\qquad(\mathrm{kN})\end{array}$} & \multirow[b]{2}{*}{ Obs./Cal. } \\
\hline & Positive & Negative & Avg & Positive & Negative & Avg & \\
\hline CW1 & 346 & -335 & 341 & 386 & -381 & 384 & 1.13 \\
\hline CW2 & 1022 & -1029 & 1026 & 1025 & -1016 & 1021 & 1.00 \\
\hline CW3 & 1205 & -1123 & 1164 & 1233 & -1232 & 1233 & 1.06 \\
\hline SW1 & 560 & -706 & 633 & 566 & -562 & 564 & 0.89 \\
\hline SW2a & 1462 & -1549 & 1506 & 1477 & -1440 & 1459 & 0.97 \\
\hline SW3 & 2355 & -1921 & 2138 & 2422 & -2118 & 2270 & 1.06 \\
\hline
\end{tabular}



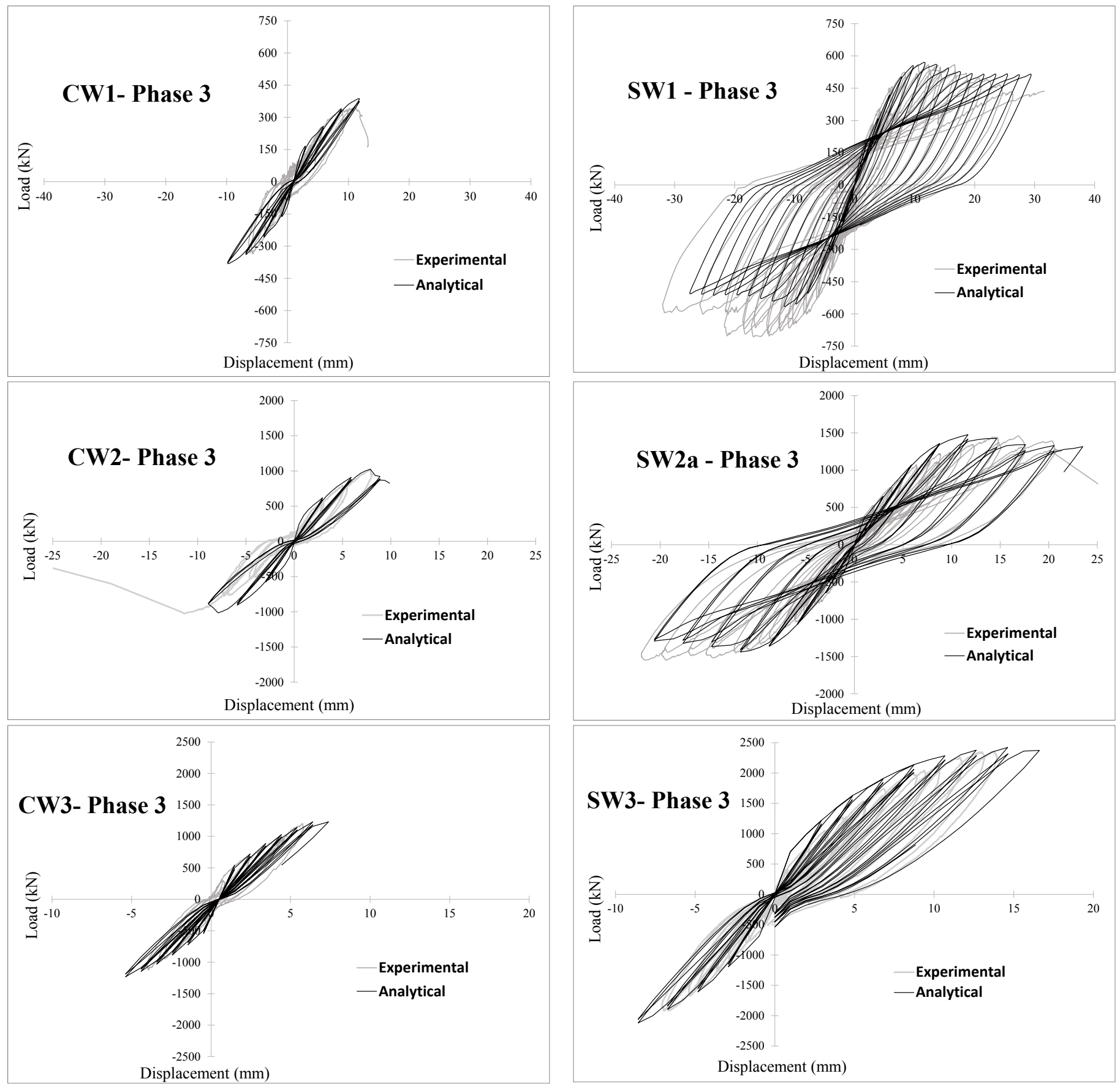

Fig. 25. Observed and calculated responses of the control and strengthened shear walls in phase 3

Table 6 compares the observed failure behaviour against the calculated failure sequence and failure mode in phase 3 . The failure sequence is accurately predicted by the analytical models. The 
failure mode is observed and predicted to be diagonal tension in CW1, CW2 and SW2a, and diagonal compression in SW1. Walls with inadequate shear reinforcement are prone to diagonal TABLE 6. Computed against measured sequence of failure (Phase 3)

\begin{tabular}{|c|c|c|c|c|c|c|c|}
\hline \multirow[b]{2}{*}{ Appr. ${ }^{\mathrm{c}}$} & \multirow[b]{2}{*}{ Spec. ${ }^{d}$} & \multicolumn{3}{|c|}{$\begin{array}{c}\text { Failure sequence }(\text { observed })^{\mathrm{a}} \\
\text { Disp. }(\mathrm{mm}), \text { Force }(\mathrm{kN})\end{array}$} & \multicolumn{3}{|c|}{$\begin{array}{c}\text { Failure sequence (calculated) })^{\mathrm{a}} \\
\text { Disp. }(\mathrm{mm}), \text { Force }(\mathrm{kN})\end{array}$} \\
\hline & & Yield & Debond & Failure Mode & Yield & Debond & Failure Mode \\
\hline \multirow[t]{3}{*}{-} & CW1 & 11,242 & $\mathrm{~N} / \mathrm{A}$ & Diag. Ten. & 9,325 & $\mathrm{~N} / \mathrm{A}$ & Diag. Ten. \\
\hline & CW2 & 9,765 & $\mathrm{~N} / \mathrm{A}$ & Diag. Ten. & 7,810 & $\mathrm{~N} / \mathrm{A}$ & Diag. Ten. \\
\hline & $\mathrm{CW}^{\mathrm{b}}$ & - & N/A & - & - & $\mathrm{N} / \mathrm{A}$ & - \\
\hline \multirow[t]{2}{*}{ First } & SW1 & 7,376 & 15,530 & Diag. Comp. & 5,366 & 15,510 & Diag. Comp \\
\hline & SW2a & 7, 909 & 16,1416 & Diag. Ten. & 6,1003 & 13,1424 & Diag. Ten. \\
\hline- & $\mathrm{SW}^{\mathrm{b}}$ & - & - & - & - & - & - \\
\hline \multicolumn{8}{|c|}{$\begin{array}{l}\text { Note: }{ }^{\mathrm{a}} \text { Yield }=\text { Yield st } \\
\text { Diagonal Compression } \\
\text { bWall specimen not tes } \\
{ }^{\mathrm{b}} \text { Appr.=Approach. } \\
{ }^{\mathrm{d}} \text { Spec. }=\text { Specimen. }\end{array}$} \\
\hline \multirow{2}{*}{\multicolumn{8}{|c|}{$\begin{array}{l}\text { tension shear failure in which, the horizontal steel reinforcement in tension is ruptured and is } \\
\text { characterised by a diagonal failure plane, as shown in Fig. 26. Diagonal compression shear failure }\end{array}$}} \\
\hline & & & & & & & \\
\hline \multicolumn{8}{|c|}{ results from localized crushing in the toes of the shear wall, caused by compressive forces } \\
\hline \multicolumn{8}{|c|}{ developed along the wall compression strut, as displayed in Fig. 26 (c). } \\
\hline \multicolumn{8}{|c|}{ When multiple CFRP layers are used on both sides of shear walls, they act as a hard laminate } \\
\hline (Lomb & d et. al 2 & 0 ; Hiotak & 2004) wh & ch increases th & exural ca & ity of the & 11 specimen \\
\hline
\end{tabular}


(a)

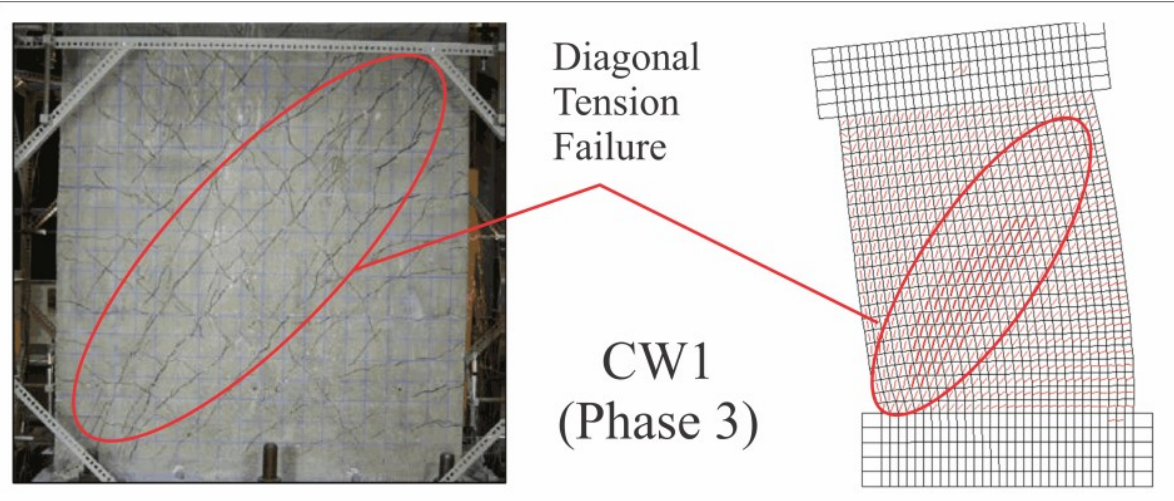

(b)

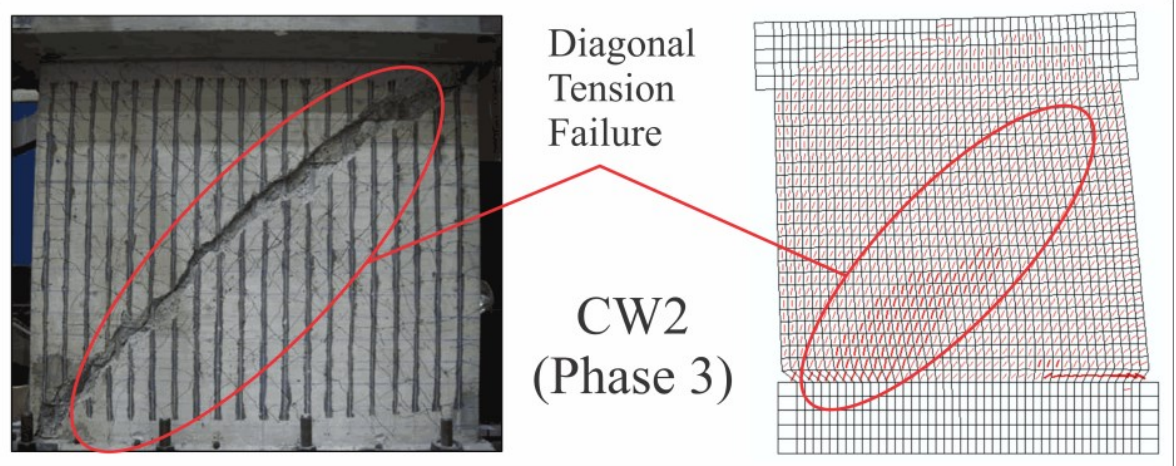

(c)

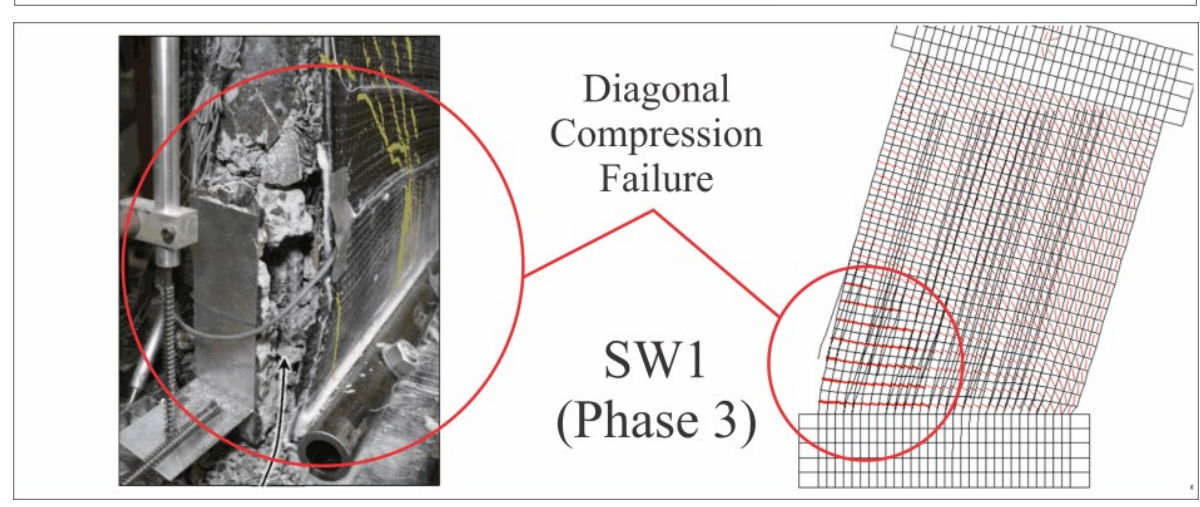

(d)

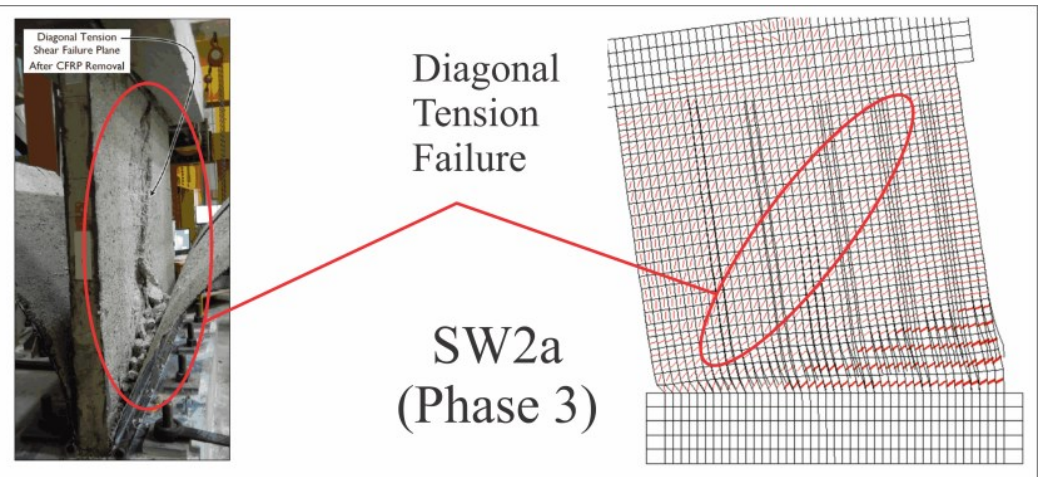

Fig. 26. Failure modes in Phase 3 shear walls, (a) CW1 (b) CW2 (c) SW1 (d) SW2a 


\section{CONCLUSIONS}

This paper first presented a brief overview of the three-phases comprehensive experimental program, that was conducted on CFRP-strengthened and repaired RC shear walls at Carleton University. During this experimental program, two mechanical anchor systems were developed and tested; namely, a steel angle anchor system and a novel tube anchor system. The experimental results confirmed the efficiency of the tube anchor system in preventing premature debonding and allowing a large portion of the high strength capacity of the CFRP sheets to be used. This study developed the first numerical model that vigorously accounts for the influence of the tube anchor system on the response of the CFRP strengthened shear walls. Two approaches were developed to model the influence of the tube anchor system using 1) link elements, or 2) springs (truss element). Moreover, the confinement effect of CFRP layers on concrete was also considered based on an independent parametric study. The analytical results correlate well with measured experimental data for key structural response parameters. To appreciate the importance of considering the effect of the anchor system, two other modelling assumptions were examined in which, significant discrepancies were found between the analytical and experimental results. The following conclusions can be made from this study:

1. The consideration of the effects of the anchor system in the analytical model are found to be critical for a reliable prediction of the nonlinear performance of the shear walls reinforced with CFRP tow sheets.

2. This study develops the first numerical model that accounts for the influence of the tube anchor system and the CFRP debonding mechanism on the response of FRPstrengthened shear walls. 
3. The calculated responses correlate well with the experimental results, which demonstrate the validity of the developed FE model.

4. The model can accurately capture the full range of shear wall behavior from ductile flexural failure of slender walls to brittle shear failure of squat walls.

5. A parametric study was conducted to investigate the confining effect of the FRP sheets on concrete.

6. The confining effect found to be more significant in squat walls than slender walls of the test program.

7. Oversimplifying the effect of development length and anchor system, using assumptions such as uniform prefect or imperfect bond between CFRP and concrete at the base of the wall, can lead to significant overestimation or underestimation of the peak strength.

8. Rational procedures such as the ones presented in this study can take into account the effects of the anchor system with reasonable accuracy. 


\section{REFERENCES}

ACI Committee. (2002). "Guide for the Design and Construction of Externally Bonded CFRP Systems for Strengthening Concrete Structures." American Concrete Institute; 440.2R-02.

Antoniades, K., Salonikios, T., and Kappos, A. (2003). "Cyclic tests on seismically damaged reinforced concrete walls strengthened using fibre-reinforced polymer reinforcement." ACI Structural Journal, 100(4), 510-518.

Cortés-Puentes, L. and Palermo, D. (2012). Modelling of RC Shear Walls Retrofitted with Steel Plates or FRP Sheets. Journal of Structural Engineering. Vol.138, No.5.

Cruz-Noguez, C. A., Lau, D. T., Sherwood, E. G., Lombard, J., and Hiotakis, S. (2014). "Seismic Behaviour of RC Shear Walls Strengthened for In-Plane Bending Using Externally Bonded CFRP Sheets." Journal of Composite Construction, ASCE.

Cruz-Noguez, C., Lau, D., Sherwood, E., S., Lombard, J., Foo, S., and Cheung, M. (2014b). Seismic behaviour of RC shear walls strengthened for in-plane bending using externally bonded CFRP sheets. Journal of Composites for Construction, 19(1):04014023.

Elnady, M. (2008), "Seismic Rehabilitation of RC Structural Walls." PhD Thesis, McMaster University, Department of Civil and Environmental Engineering.

El-Sokkary, H., Galal, K., Ghorbanirenani, I., Leger, P., \& Tremblay, R. (2013). Shake Table Tests on CFRPRehabilitated RC Shear Walls. Journal of Composites for Construction, 79-90.

Grelle, S. V., and Sneed, L. H. (2011). An Evaluation of Anchorage Systems for Fibre-Reinforced Polymer (CFRP) Laminates Bonded to Reinforced Concrete Elements. Proceeding of Structures Congress, 1-12.

Hassan, A. and Lau, D. (2016). Modelling debonding mechanisms in CFRP strengthened reinforced concrete shear walls for improved seismic performance. In 7th International Conference on Advanced Composite Materials in Bridges and Structures. Vancouver, Canada.

Hiotakis, S. (2004). "Repair and Strengthening of Reinforced Concrete Shear Walls for Earthquake Resistance Using Externally Bonded Carbon Fibre Sheets and a Novel Anchor System." Master's thesis, Department of Civil and Environmental Engineering, Carleton University.

Hiotakis, S., Lau, D., and Londono, N. (2004). Research on seismic retrofit and rehabilitation of reinforced concrete shear walls using CFRP materials. In Proceedings of the Joint National Science Council Taiwan National Research Council of Canada NSC-NRC Workshop on Construction Technologies, pages 17-26.

Hordijk, D.A., Cornelissen, H.A., Reinhardt, H.W. (1986). "Experimental determination of crack softening characteristics of normal weight and lightweight concrete". HERON Vol. 31, No. 2

Kanakubo, T., Aridome, Y., Fujita, N., and Matsui, M. (2000). Development of Anchorage System for CCFRP Sheet in Strengthening of Reinforced Concrete Structures. Proceeding of 12th World Conference on Earthquake Engineering, 1831-1839.

Kaufmann, W. and Marti, P., (1998). "Structural Concrete: Cracked Membrane Model", ASCE Journal of Structural Engineering, Vol. 124, No. 12, pp. 1467-1475.

Khalil, A., and Gobarah, A. (2005). Behaviour of Rehabilitated Shear Walls. Journal of Earthquake Engineering 9:3, 371-391.

K., Fields and H., Bischoff. (2004). Tension Stiffening and Cracking of High-Strength Reinforced Concrete Tension Members. ACI Structural Journal. 101. 447-456.

Lau, D.T., Woods, J.E., (2017). A Concentric Tube Anchor System for CFRP Retrofit of RC Structural Walls under Extreme Loads. International Journal of Protective Structures, Vol 9 (1): 77-98, March 2018.

Lombard, J., Lau, D., Humar, J., Foo, S. and Cheung, M. (2000). "Seismic strengthening and repair of reinforced concrete shear walls", Proc. of 12th World Conf. on Earthquake Eng., paper No. 2032.

Lu, X., Teng, J., Ye, L., \& Jiang, J. (2005). Meso-scale Finite Element Model for CFRP Sheets/Plates Externally Bonded to Concrete. Eng. Struct., 27:6, 564-575. 
Oehler, D.J., Park, S.M. and Mohamed Ali, M.S. (2003). "A structural engineering approach to adhesive bonding longitudinal plates to RC beams and slabs." Composites, Part A, 34(12), 887-897.

Paterson, J. and Mitchell, D. (2003). "Seismic Retrofit of Shear Walls with Headed Bars and Carbon Fibre Wrap." Journal of Structural Engineering, ASCE, (129)5, 606-614.

Sadeghian, V., \& Vecchio, F. (2016). Application of Multi-Scale Modelling on Large Shear-Critical Reinforced Concrete structural Systems Repaired with CFRP Sheets. Bentham Science Publishers, 2-3.

Sato, Y. and Vecchio, F.J., (2003). "Tension Stiffening and Crack Formation in RC Members with CFRP Sheets", ASCE Journal of Structural Engineering, Vol. 129, No 6, pp. 717-724

Seckin, M. (1981). Hysteretic behaviour of cast-in-place exterior beam-column-slab subassemblies, Ph.D. Thesis, Department of Civil Engineering, University of Toronto

Smith, S. T., and Teng, J. G. (2003). Shear Bending Interaction in Debonding Failures of CFRP plated RC Beams. Advanced Structural Engineering Journal Vol. 6:3, 183-199.

Teng, J. G., Chen, J. F., Smith, S. T., and Lam, L. (2002). CFRP-strengthened RC structures, Wiley, London.

Vecchio, F. (1999). Towards cyclic load modelling of reinforced concrete, ACI Struct. J., Vol. 96, pp. 193-202.

Vecchio, F. (2000). Disturbed Stress Field Model for Reinforced Concrete: Formulation. Journal of Structural Engineering, 126(9), 1070-1077.

Vecchio, F. J., and Bucci, F. (1999). "Analysis of repaired concrete structures.", Journal of Structural Engineering, 125(6), 644-652.

Vecchio, F., and Collins, M. (1986). The Modified Compression Field Theory for Reinforced Concrete Elements Subject to Shear. ACI Structural Journal, 83(2), 219-231.

Wong, S. Y., and Vecchio, F. J. (2003), "Towards modelling of reinforced concrete members with externally bonded fiber-reinforced polymer composites", ACI Struct. J., 100(1), 47-55.

Wong, P. S., Vecchio, F. J., Trommels, H. (2013). VecTor2 and FormWorks user's manual (Second edition). Toronto, ON, Canada: University of Toronto, Department of Civil Engineering.

Woods, J. E. (2014), "Seismic Retrofit of Deficient Reinforced Concrete Shear Walls using Fibre-reinforced Polymer Sheets: Experimental Study and Anchor Design" MASc Thesis, Carleton University, Department of Civil and Environmental Engineering.

Woods, J., Lau, D. and Cruz-Noguez, C. (2016). In-plane Seismic Strengthening of Nonductile Reinforced Concrete Shear Walls using Externally Bonded CFRP Sheets. Journal of Composites for Construction, 20(6).

Woods, J. E. (2018), "Advances in Retrofit and Testing of Reinforced Concrete Shear Walls." PhD Thesis, Carleton University, Department of Civil and Environmental Engineering.

Woods, J., Lau, D. and Erochko, J. (2020). Evaluation by Hybrid Simulation of Earthquake-Damaged RC Walls Repaired for In-Plane Bending with Single-Sided CFRP Sheets. Journal of Composites for Construction, 24(6). 


\section{APPENDIX A}

\section{A.1 Material Properties in Phase 2}

\section{A.1.1 Steel}

The reinforcing steel used in the wall specimens was grade 400 .

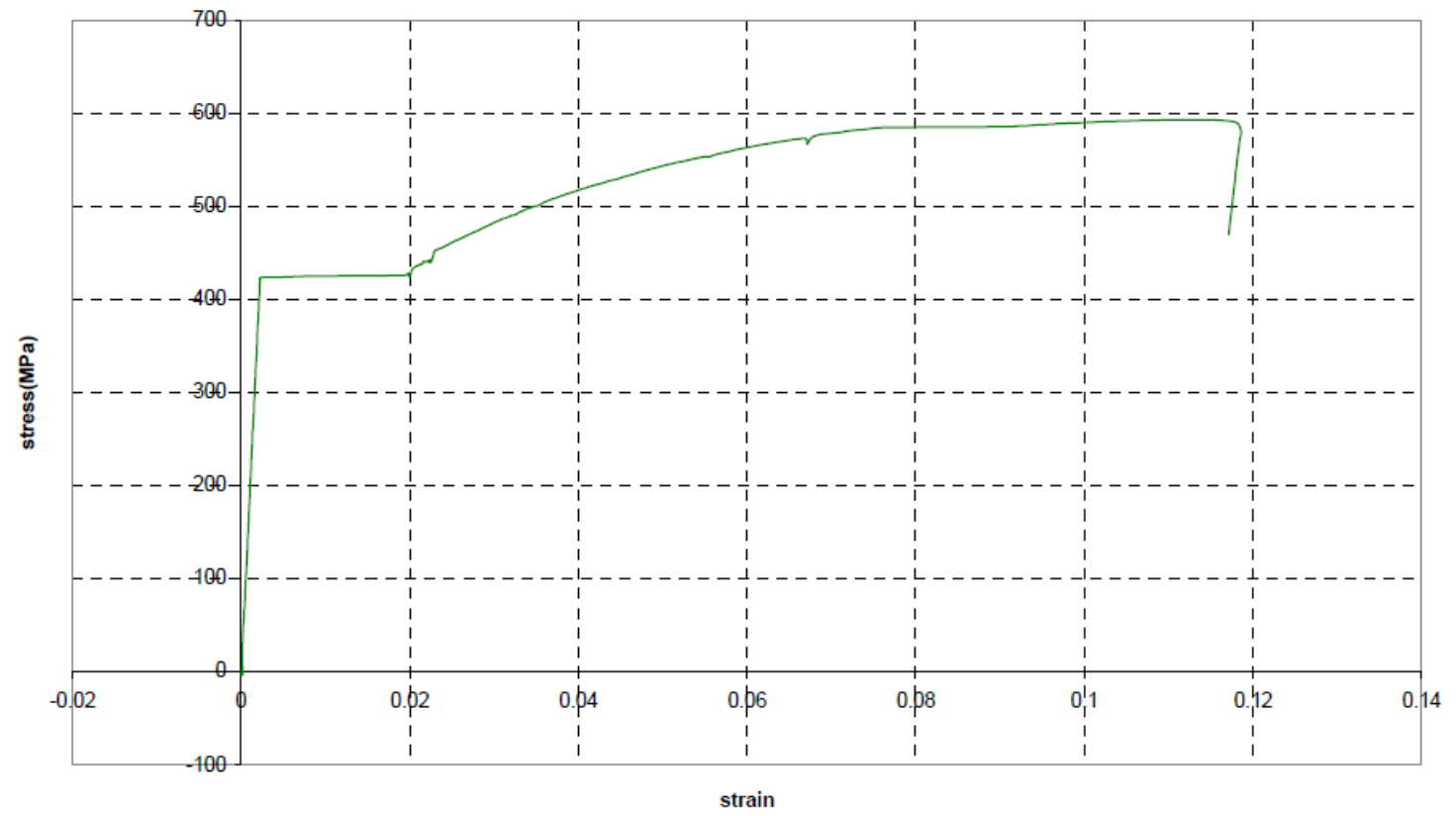

Fig. A.1.1. Stress-Strain curve for No.10 steel rebars (from Hiotakis 2004)

\section{A.1.2 Concrete}

TABLE A.1.1. Concrete cylinder test results (from Hiotakis 2004)

\begin{tabular}{cccccc}
\hline Specimen & $\begin{array}{c}\text { Age (at test) } \\
\text { (Days) }\end{array}$ & $\begin{array}{c}\mathrm{f}^{\prime c}(28 \text { days }) \\
(\mathrm{MPa})\end{array}$ & $\begin{array}{c}\text { fr (28 days) } \\
(\mathrm{MPa})\end{array}$ & $\begin{array}{c}\mathrm{f}^{\prime} \mathrm{(at} \text { test) } \\
(\mathrm{MPa})\end{array}$ & $\begin{array}{c}\text { fr (at test) } \\
(\mathrm{MPa})\end{array}$ \\
\hline CW2 & 175 & 35.9 & 3.0 & 36.2 & 3.1 \\
RW2 & 254 & 35.9 & 3.0 & 38.7 & 3.5 \\
SW1-2 & 203 & 35.9 & 3.0 & 36.4 & 3.3 \\
SW2-2 & 213 & 35.9 & 3.0 & 39.0 & 3.3 \\
SW3-2 & 220 & 35.9 & 3.0 & 38.6 & 3.5 \\
\hline
\end{tabular}




\section{A.1.3 FRP Sheet}

TABLE A.1.2. FRP sheets characteristics (from Hiotakis 2004)

\begin{tabular}{ll}
\hline Specification & MRL-T7-200W(RENO) \\
Weight / unit area & $200 \mathrm{~g} / \mathrm{m} 2$ \\
Tensile strength & $4800 \mathrm{MPa}$ \\
Tensile modulus & $230.5 \mathrm{GPa}$ \\
Thickness & $0.11 \mathrm{~mm}$ \\
Ultimate strain & $1.7 \%$ \\
Width of sheet & $50 \mathrm{~cm}$ \\
\hline
\end{tabular}

\section{A.2 Steel Reinforcement in the Wall Specimens in Phase 2}

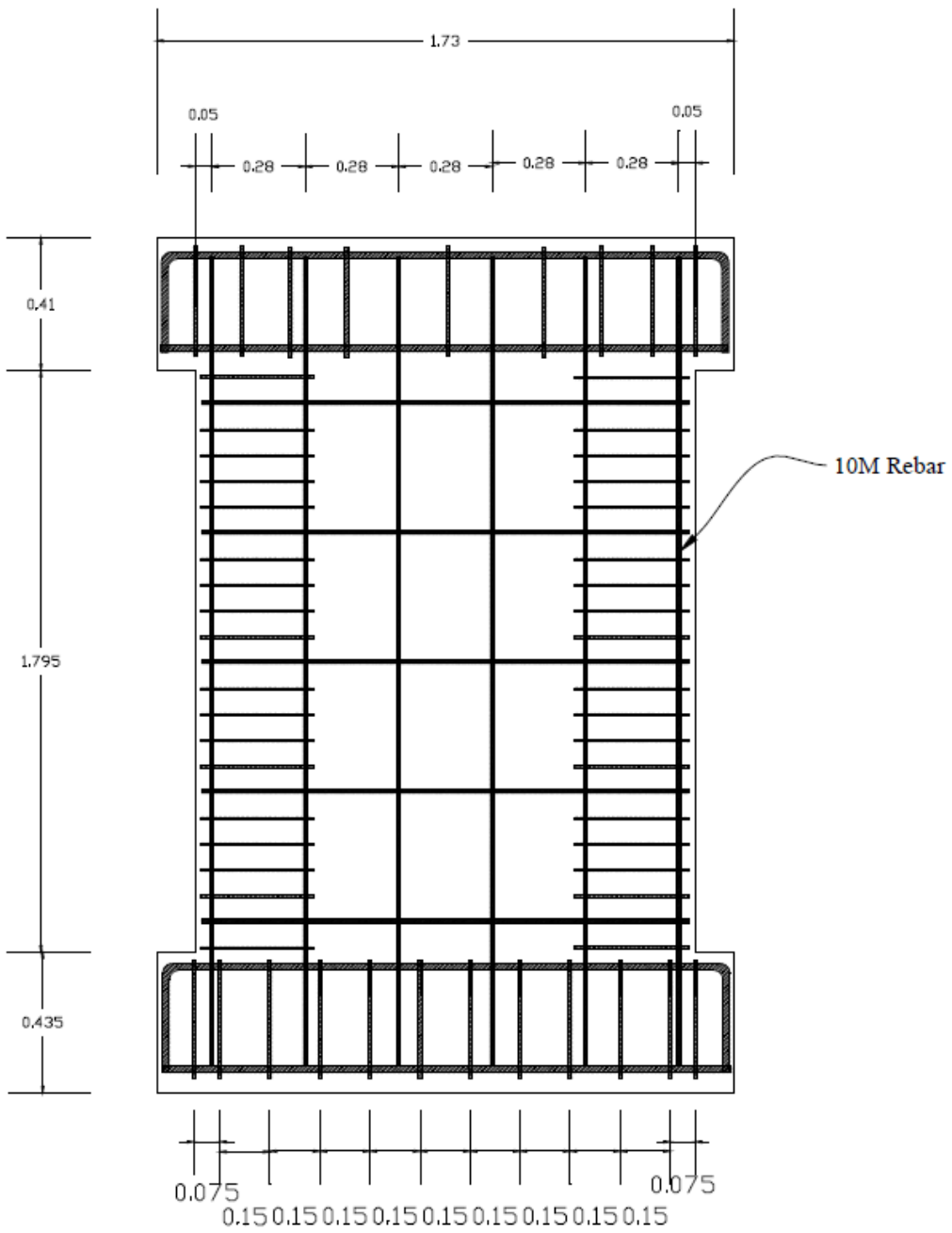

Fig. A.2.1. Side view of the specimens' steel reinforcement (from Hiotakis 2004) 


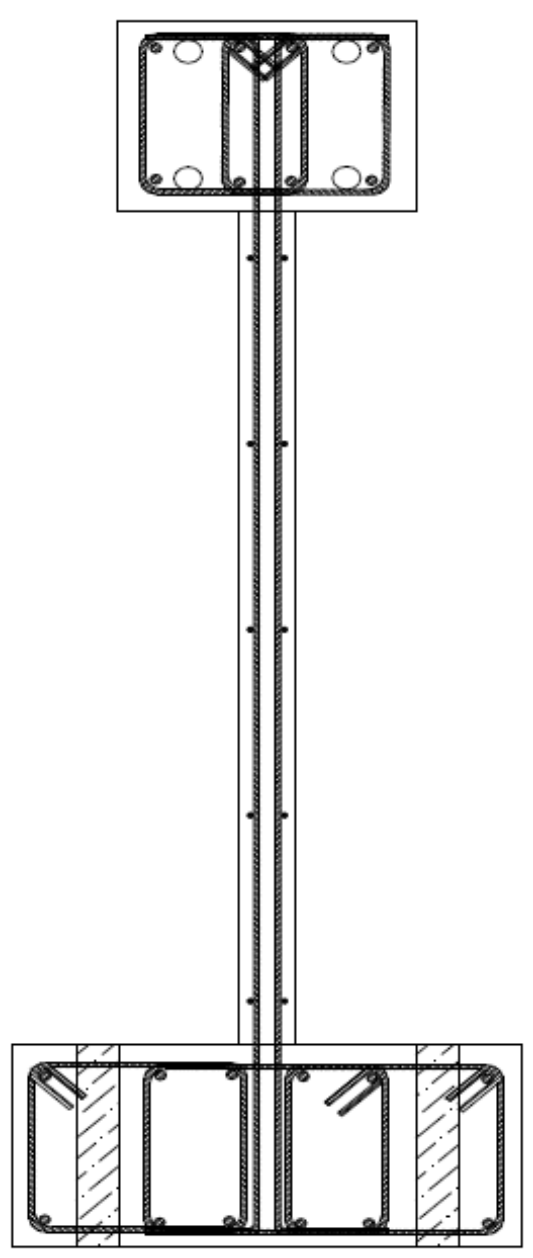

Fig. A.2.2. Front view of the specimens' steel reinforcement (from Hiotakis 2004)

\section{A.3 Material Properties in Phase 3}

\section{A.3.1 Steel}

TABLE A.3.1 Steel reinforcement material properties (from Woods 2018)

\begin{tabular}{ccccc}
\hline Property & 6M Bars & 10M Bars & 15M Bars & 20M Bars \\
\hline $\mathrm{f}_{\mathrm{y}}(\mathrm{MPa})$ & 415 & 440 & 452 & 480 \\
$\mathrm{E}_{\mathrm{s}}(\mathrm{GPa})$ & 160 & 170 & 188 & 208 \\
$\varepsilon_{\mathrm{y}}(\mathrm{mm} / \mathrm{mm})$ & 0.0026 & 0.0026 & 0.0024 & 0.0023 \\
$\varepsilon_{\mathrm{u}}(\mathrm{mm} / \mathrm{mm})$ & 0.012 & 0.141 & 0.115 & 0.137 \\
\hline
\end{tabular}




\section{A.3.2 Concrete and FRP}

TABLE A.3.2 Concrete and CFRP material properties (from Woods 2018)

\begin{tabular}{|c|c|c|c|c|c|c|c|c|c|}
\hline \multicolumn{4}{|c|}{ Concrete Properties } & & & \multicolumn{4}{|c|}{ CFRP Properties } \\
\hline \multicolumn{2}{|c|}{ Foundation Blocks } & \multicolumn{2}{|c|}{ Wall Panels } & \multicolumn{2}{|c|}{ Cap Beams } & \multicolumn{2}{|c|}{ Dry Fibre } & \multicolumn{2}{|c|}{ Cured Laminate } \\
\hline$f_{c}^{\prime}(\mathrm{MPa})$ & 73.4 & $f_{c}^{\prime}(\mathrm{MPa})$ & 19.1 & $f_{c}^{\prime}(\mathrm{MPa})$ & 64.8 & $f_{f}(\mathrm{MPa})$ & 4000 & $\left.f_{f}\right)(\mathrm{MPa})$ & 931 \\
\hline$E_{c}(G P a)$ & 35.8 & $E_{c}(\mathrm{GPa})$ & 19.2 & $E_{c}(\mathrm{GPa})$ & 39.4 & $E_{f}(\mathrm{GPa})$ & 230 & $E_{f}(\mathrm{GPa})$ & 83.8 \\
\hline$\epsilon_{c}^{\prime}$ & 0.0028 & $\epsilon_{c}^{\prime}$ & 0.0018 & $\epsilon_{c}^{\prime}$ & 0.0019 & $\epsilon_{f u}$ & 0.017 & $\epsilon_{f u}$ & 0.01 \\
\hline$\epsilon_{u}^{\prime}$ & - & $\epsilon_{u}^{\prime}$ & 0.0042 & $\epsilon_{u}^{\prime}$ & - & $t_{f}(\mathrm{~mm})$ & 0.11 & $t_{f}(\mathrm{~mm})$ & 0.012 \\
\hline
\end{tabular}




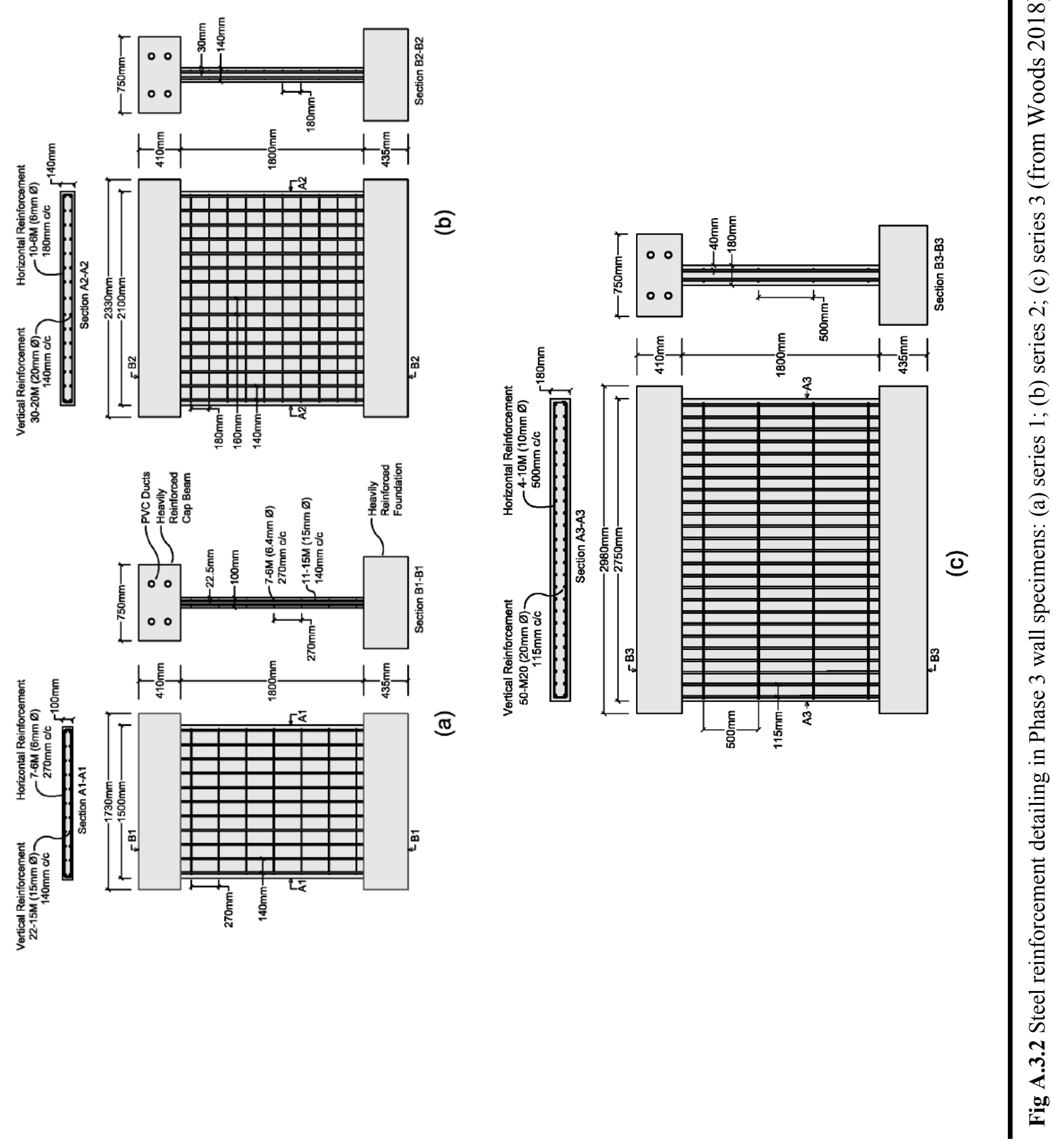




\section{APPENDIX B}

The steps to derive equation (9):

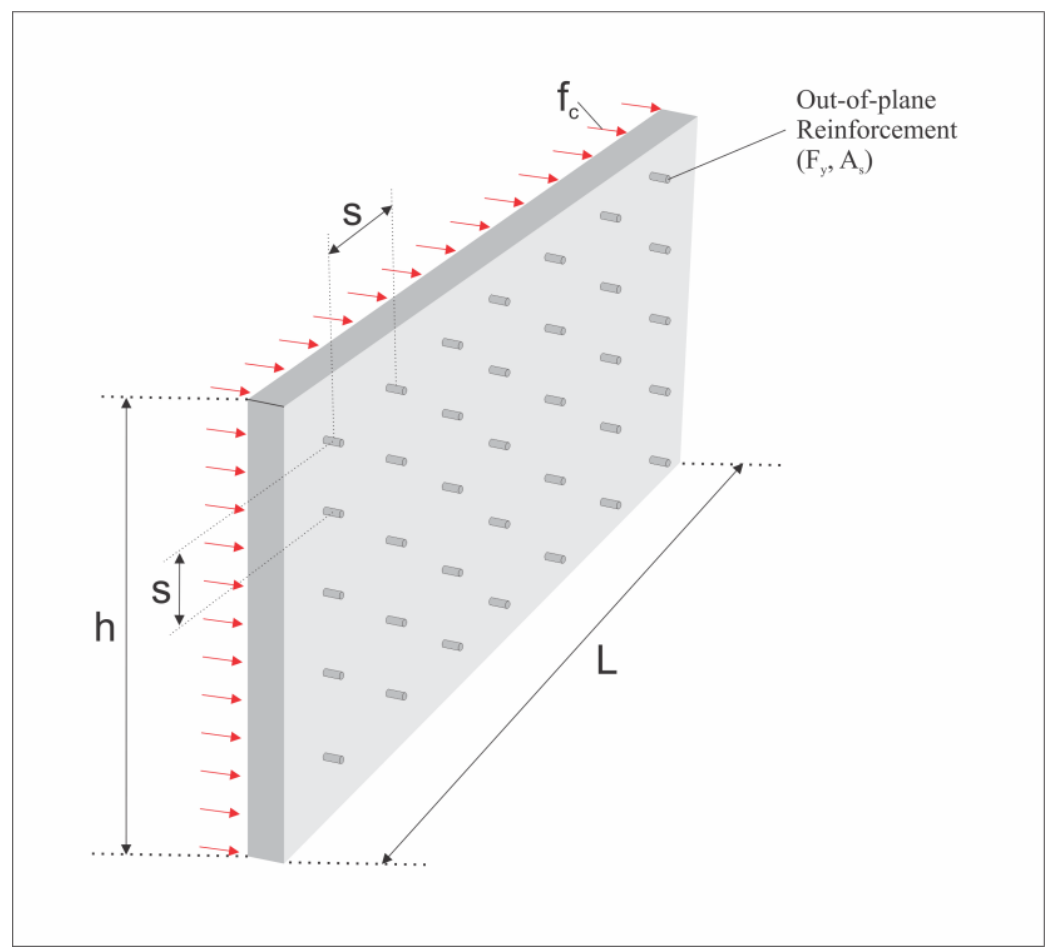

Fig B.1 Finding the equivalent OOP reinforcement ratio

As can be seen in Fig B.1.:

$$
\begin{gathered}
f_{c} \cdot h \cdot L=\left(A_{s} \cdot F_{y}\right)\left(\frac{L}{s}\right)\left(\frac{h}{s}\right) \\
f_{c}=A_{s} \cdot \frac{F_{y}}{s^{2}}
\end{gathered}
$$

Rearranging equation (I):

Based on the definition of reinforcement ratio: $\quad \rho=\frac{\sum A_{s}}{A_{c}}=\frac{A_{s} \cdot\left(\frac{L}{s}\right) \cdot\left(\frac{h}{s}\right)}{L \cdot h}=\frac{A_{s}}{s^{2}}$

From (I) and (III):

$$
f_{c}=\rho \cdot F_{y}
$$

